\title{
Effects of Reconstruction Planning on the Utility of Social Capital in Minamisanriku, Miyagi after the 2011 Great East Japan Earthquake
}

\author{
Kayleigh Ward
}

check for updates

Citation: Ward, Kayleigh. 2021. Effects of Reconstruction Planning on the Utility of Social Capital in Minamisanriku, Miyagi after the 2011 Great East Japan Earthquake. Social Sciences 10: 254. https://doi.org/ 10.3390/socsci10070254

Academic Editor: Francis O. Adeola

Received: 31 May 2021

Accepted: 30 June 2021

Published: 2 July 2021

Publisher's Note: MDPI stays neutral with regard to jurisdictional claims in published maps and institutional affiliations.

Copyright: (C) 2021 by the author. Licensee MDPI, Basel, Switzerland. This article is an open access article distributed under the terms and conditions of the Creative Commons Attribution (CC BY) license (https:// creativecommons.org/licenses/by/ $4.0 /)$.
Department of Sociology, Michigan State University, East Lansing, MI 48824, USA; wardkayl@msu.edu

\begin{abstract}
This mixed-methods community-based participatory research project is set in the rural coastal community of Minamisanriku, Miyagi. Ten years after the 2011 Great East Japan Earthquake, this study investigates whether and to what extent social capital acts as an asset to drive economic growth, recovery, collaboration, and decision making for residents to address social and economic problems as they perceive them. The connection between reconstruction planning and recovery is also investigated. Primary data collection methods include a conceptual social capital mapping exercise $(n=200)$ to document resident bonding, bridging, and linking capital relationships $(n=1994)$, and semi-structured interviews $(n=70)$ to capture how residents with high linking capital do or do not utilize it. Participant observation and secondary data analysis contextualized resident maps and interviews. Overall, the study results suggest that the utility of social capital is highly sensitive to the cultural norms of social and power hierarchies, that it fortifies in group-out group dynamics, and enables residents to address immediate needs, but lacks the ability to enable residents to use the resources and information entrenched in their social networks and other structures effectively due to intermediating issues of unequal development of social and economic infrastructure across districts and other community disparities that emerge through the reconstruction process.
\end{abstract}

Keywords: social capital; disaster studies; linking social capital; decision making; social infrastructure; reconstruction planning; disaster policy; earthquake disaster; tsunami disaster

\section{Introduction}

While major strides have been made in reconstructing communities affected by the 2011 Great East Japan Earthquake, there is still much to do with community recovery. In response to this large-scale disaster, the national government assisted in the reconstruction of affected communities. However, policies had limited effects on withstanding social issues. Post-disaster, recovery difficulties in these rural communities result from both social and economic woes. Historically economic development and private development projects were sought after to accomplish recovery in Japan. However, the success of economic projects is mitigated by social problems, especially concerning limited resident input from affected communities and the types of projects sponsored by the government and private industry. Despite targeted intervention, issues of aging, depopulation, and industrial decline have not slowed significantly enough to overcome the initial physical, human, and environmental losses from the disaster.

One main factor to promote recovery is social capital. Social capital as networks of relationships among individuals, groups, and organizations with shared norms, values, and understandings, living and working in communities has been found to play a key role in creating positive recovery outcomes in various cultural settings (James and Paton 2016; Tierney 2019). However, social capital as a critical component of disaster management, disaster risk reduction, and disaster studies in Japan was not largely considered until after the 1995 Kobe Earthquake (Great Hanshin-Awaji Earthquake), and further after the 2011 Great East Japan Earthquake. Following the Great East Japan Earthquake, there is growing 
interest surrounding the importance of social capital in post-disaster communities in Japan and elsewhere, especially as to how it pertains to social and economic recovery (Shaw 2014). It is in this space that this study and other social capital disaster studies are situated.

This mixed-methods study takes place in the community of Minamisanriku, Miyagi and uses different types of social capital to investigate connections between recovery and reconstruction planning. Special attention is given to the social and economic effects of reconstruction planning. Additionally, the goal of this study is to answer whether and to what extent social capital drives economic growth, recovery, collaboration between groups, and inclusive decision making. Especially as the literature on long-term social capital effects on disaster recovery is much less developed in Japan, focusing on whether and to what extent these driving effects are present in the long term is critically important in clarifying the utility of social capital (Shaw 2014; Aldrich 2012a). The utility of social capital and its importance in disaster studies are covered in the following section, with special consideration for this study discussed in Section 1.4.

\subsection{The Uses, Roles, and Functions of Social Capital}

Following the rise of social capital studies in the 1980s and 1990s, social capital's capability and flexibility to address a variety of social and economic ills have been well documented. Economically, well-developed social capital increases economic productivity and growth, and acts as a resource to access financial capital, especially in vulnerable communities (Knack and Keefer 1997; Gold and Light 2000). It also reduces crime, poor health outcomes, and economic burdens on individuals and households (DiIulio 1996; Torsvik 2000). Socially and politically rich social capital increases civic engagement and civic activities, and can foster forms of democratic governance (Putnam 2000; Putnam et al. 2004; Fukuyama 2001).

Additionally, social capital as a composite of social networks, reciprocity, trust, organizational involvement, and a variety of other factors can be used to stimulate social cohesion and collaboration between groups, as well as power sharing across groups, and can provide individuals with the ability to transform social capital into other useable capitals such as to access aid (financial capital) or educational resources (human capital) (Putnam 2000; Flora et al. 2016). In other cases, cross-collaborations can help cultivate individual problem-solving skills and leadership development to promote civic engagement further (Pigg et al. 2015).

Despite the proliferation of studies documenting social capital as a positive asset, there are also negative consequences to rich social capital, especially in group settings. Social capital requires individuals to continually maintain relationships with individuals, organizations, and institutions. As such, the commodity of time is a barrier to cultivating social capital. As a result, social capital is not uniform across genders, ages, occupations, classes, or geographical locations (Bourdieu 1986; Portes 2014; Portes and Landolt 2000). This inequity of social capital, especially in power dynamics, is often undiscussed in both non-disaster and disaster studies that employ it as a theoretical framework. A seminal piece on this topic by Portes (2014) notes that communities with too much social capital can reinforce harmful norms and behaviors. Additionally, over-investment can force conformity and exclude others from accessing other social or economic needs due to relationship demands (e.g., too many familial obligations or in group-out group conflicts) (Levine et al. 2014; Waldinger 1995).

Secondly, social capital is very sensitive to change, such as those caused by economic depressions, political unrest, disasters, or other major societal changes. (James and Paton 2016; Gill 2014). If proper social and economic interventions are lackluster or delayed, the use, role, and function of social capital can be heavily reduced or even continually eroded, mitigating possible benefits (Aldrich 2012a; Shiraishi and Matoba 2019).

However, when utilized well and in certain contexts, social capital can provide aid to communities and individuals who lack access to other forms of capital, especially financial. In disaster contexts, social capital and its forms may be notably more important, especially 
for communities who have limited economic resources or are otherwise disenfranchised (Mathbor 2007; Norris et al. 2008; Marín et al. 2015; Sadri et al. 2018).

\subsection{Forms of Social Capital—Bonding, Bridging, and Linking}

The definition of social capital applied in this study refers to the connections between people and institutions, trustworthiness that facilitates cooperation, and the actual or potential resources connected to individual or group social networks. To consider social capital in disasters and its effects for communities, there are three types of social capital under investigation. These include bonding, bridging, and linking. Bonding social capital refers to close family relationships and other close friendships (Briggs 2003). In addition, bonding capital also includes connections between similar people, such as in age, gender, language, location, occupation, or ethnicity (James and Paton 2016). Bridging social capital refers to relationships between people and social groups who are dissimilar, such as in age, ethnicity, and class among other divisive socioeconomic and sociodemographic characteristics (Szreter and Woolcock 2004; Hawkins and Maurer 2010). These relationships provide access to different resources, such as information or jobs, that an individual may not have access to in their group. Linking social capital refers to relationships with individuals who hold power or authority, usually within an institution (Putnam et al. 2004; Woolcock 2001). Individuals with access to linking capital are more likely to have the capacity to engage power structures and other forms of decision making.

Since this study is situated ten years on from the 2011 disaster, strong emphasis is placed on linking social capital as this type is critical to long-term positive recovery. The importance of linking capital is primarily supported by Aldrich's work. Individuals with direct influence on decision making, such as town politicians or other high-status individuals, are a good predictor of recovery outcomes. (Aldrich and Ono 2016). Additionally, those with access to linking capital are more likely to participate or attempt participating in town hall meetings, neighborhood associations, and other resident organization groups (Tierney 2019; Aldrich 2012a; James and Paton 2016). As a result, whether linking social capital is facilitated by social ties, relations with government, politicians, or other participatory systems, it is argued to be the most important form of social capital for long-term recovery (Aldrich 2012b; Aldrich and Ono 2016; James and Paton 2016).

Secondarily, bonding and bridging capital are also considered. Bonding capital has limited application in long-term recovery and is thought to be useful in the short term or the immediate aftermath to gain needed resources (Hurlbert et al. 2001). Bonding relationships primarily provide emotional and financial support to people immediately following a disaster, whereas bridging and linking capital are necessary for long-term needs and healthy community redevelopment (Hawkins and Maurer 2010). The utility of these social capitals may emerge as significant in Minamisanriku as reconstruction planning is a contentious issue across groups and is pointed to as the primary source of differences by residents, indicating that redevelopment may have significant negative consequences on recovery. These consequences, if present, may be reflected in resident and district relationships as well as in the richness of social capital that residents possess. The application and outcomes of social capital and its forms in disaster studies are especially notable in Japan.

\subsection{Application and Outcomes of Social Capital in Disaster Studies in Japan}

Social capital disaster studies in Japan increased in number in the 1990s, becoming a recognized way to investigate the consequences of disaster policy and disaster management, and to measure and understand a variety of critical social and economic topics, such as health and well-being, vertical and horizontal power structures, economic growth, recovery patterns, social infrastructure, resiliency, and depopulation (Shaw 2014). This interest in social capital arose after the 1995 Kobe Earthquake, when more than 1 million people served as disaster volunteers (Fukao 2019). Becoming known as the year of volunteerism (or volunteer gannen), civil society was catapulted forward with new reforms on non- 
profits and volunteer organizations. This period saw a rise in studying the roles of mutualhelp organizations, volunteerism, NPOs, NGOs, and other civil groups in providing disaster relief and recovery where centralized governance had failed to assist (Shiraishi and Matoba 2019; Fukao 2019). In this space, grassroot activists and scholars alike sought to capture the power of residents and volunteers. Since the 1990s, social capital disaster studies have expanded their scope from volunteerism, organizational networks. and other civil organizations to greater discussions on power structures, governance, resilience, collaboration, and other important facets of social infrastructure affecting recovery. Between the 1990s and today, social capital disaster studies have captured three main features of social capital-its ability to act as an economic driver, recovery driver, and collaboration driver.

\subsubsection{Social Capital as an Economic Driver}

Social capital can promote economic growth. Here, economic growth primarily refers to the creation of new jobs in the tertiary sector and the creation of new businesses, entrepreneurial projects, and industry development (Shaw 2014; Aldrich 2012b). Shimada (2015) evaluated the connection between economic growth and social capital using timeseries-cross-section data from 47 prefectures over 30 years spanning between 1981 and 2012. Using proxies for social capital, Shimada found that social capital encourages individuals to return to their homes and to stay, in addition to stabilizing the economy and increasing job growth. Others note that business start-ups are more common in communities with rich social capital (Todo et al. 2013). Expanding on this point further, Shimada (2017) found strong economic implications for social capital as it generated more jobs than any other indicator and was the "factor that created differences in the pattern of recovery among wards" after the Kobe Earthquake (p. 501).

\subsubsection{Social Capital as a Recovery Driver}

Beyond these economic effects, in a string of different studies in Japan, Aldrich (2010, 2011 ,2012b) repeatedly found that social capital is important to faster recovery, but that also as a measure, social capital is better at capturing why communities recover faster when controlling for conventional economic indicators after the 1923 Tokyo Earthquake (Aldrich 2012b). Further, Aldrich (2011) carried out a study on the Great Hanshin-Awaji Earthquake based on the number of non-profit organizations (NPOs) that were created per capita as proxies for social capital as well as population growth as proxies for recovery. Across five indicators, namely social capital, population density, earthquake damage, social inequality, and economic conditions, social capital was the strongest determinant of disaster recovery rates (Aldrich 2011). These findings are echoed by Yamamura (2010), who investigated the role that social capital plays in reducing the damage associated with natural disasters by exploring the preventive role of social capital. Their study concluded that the existence of rich social capital helps to mitigate damage and found that the risks associated with natural disasters make individuals act more collectively, accelerating recovery (Yamamura 2010).

\subsubsection{Social Capital as a Collective Action Driver}

Shaw (2014) notes that rich social capital can enhance the performance of social actors. They explored bridging social capital within and outside damaged areas, bonding social capital among neighbors, and trust between residents and government (i.e., linking social capital). They found that individuals who join NPOs foster close connections and work toward common interests, which contributes to bridging social capital (Shaw 2014). Furthermore, Inaba (2011) investigated social capital in terms of cooperation and trust, contending that social capital supports victims during and after the occurrences of disasters, especially in cases where the government fails to implement adequate measures. In such cases, Schellong (2008) argues that social capital integrates resources entrenched in social structures and networks that a community can mobilize to access critical resources, such as 
information. For instance, a group with extensive trustworthiness can accomplish much more during a disaster than a comparable group with weak ties and structural holes. In this regard, social capital aids in the efficiency of information diffusion by encouraging supportive behavior and minimizing redundancy and as such leads to low transaction costs of acquiring information.

Ye and Aldrich (2019) underscore the critical nature of collective action and social capital by investigating how social ties interact with vulnerability variables such as socioeconomic status and age. They note that while there is heavy investment into physical infrastructure to mitigate future shocks in Japan, the authors reinforce the growing call to adequately invest in social infrastructure, so communities can better collaborate and cooperate to manage adverse disaster impacts.

\subsubsection{Opposing Arguments to Social Capital Disaster Studies}

In contrast, Gill (2014) argues that most studies proving a positive relationship between social capital and disaster recovery do not recognize that social capital may also exclude community members. In this way, Gill has a very similar stance to Portes (2014); Waldinger (1995); and Bourdieu (1986) in that social capital is not an equal resource, and that high social capital can enforce problematic rules, policies, and norms. Gill (2014) points to Japanese bureaucratic culture as creating negative effects, due to its overly rigid insistence on fair shares and equality, rather than equity.

Gill's argument is supported by Sasaki et al. (2020) who argue that social capital can characterize too strong cohesion that rejects outsiders or may not stop bad norms and culture. For instance, after the Great East Japan Earthquake, women were obligated to get up at 5:00 a.m. and cook at shelters, otherwise they would not be allowed in (Sasaki et al. 2020). Strong social capital which embraces enforcing gender stereotypes may not lead to positive recovery outcomes for all individuals. In this case, social capital perpetuates gender-based assumptions, which can put women in conflict with local and state authorities, their colleagues, or other members of their peer group.

\subsection{Social Capital Considerations for This Study}

Scholars believe that social science has only started generating replicable knowledge regarding factors that facilitate post-crisis recovery. However, across repeated studies and beyond the measures of damage control, economic conditions, population density, and inequality, the social networks, community organizations, institutional relations, and other proxies of social capital continue to be strong predictors of post-disaster recovery (Aldrich 2012a; Shaw 2014; James and Paton 2016; Tierney 2019). As such, this study focuses on the effects of the Great East Japan Earthquake by measuring resident social capital to illustrate and frame a discourse on the effects of disaster management and policy on recovery patterns with consideration for age, gender, location, relationships, strong and weak ties, as well as the social and economic conditions at the case site. Secondly, three types of social capital, bonding, bridging, and linking, are used to investigate the relationship between these variables and recovery. This analysis is complemented by interviews ensuring that concerns by Gill and others are addressed, such that individuals with high social capital can share their views on their decision making, satisfaction, and influence. This study corroborates and challenges findings from other social capital disaster studies as to how social capital can act as an asset to drive economic growth, recovery, collaboration, and decision making. Especially, the study results support some aspects of the collaborative capacity of social capital in small groups (Inaba 2011; Shaw 2014) and recognize how norms restrict the use of social capital (Gill 2014; Sasaki et al. 2020; Kaneko 2017). Secondly, the study results challenge the extent to which social capital can drive social and economic recovery (Shaw 2014; Aldrich 2012a; Yamamura 2010; Shimada 2017). Overall, this study contributes a more nuanced view of the utility of social capital in disaster contexts and offers new insights into the role of linking social capital. 


\section{Methodology \\ Community-Based Participatory Research}

This study adopts a community-based participatory research methodology (CBPR). CBPR is used to frame the research process, with a distinctive focus on fostering community participation through the maintenance of partnerships (e.g., community services organizations, local associations). CBPR is primarily used in vulnerable, disenfranchised, or otherwise isolated communities who are over-studied or otherwise have negative experiences with traditional research (Minkler and Wallerstein 2005). Between visits in 2014, 2016, 2017, and 2018, there has been a rise in what we might call "drive-by research" in the community, with many researchers (foreign and Japanese) stepping in and out of the community within a few weeks with very little accountability or responsibility to engage participants and the community critically. As a result, many in Minamisanriku have experienced researchers unethically leaving the field with little knowledge as to how their stories and information is being used to benefit the community. As a result, CBPR is sensitive to these pitfalls of traditional research, where outcomes fail to solve community disparities and where projects do not invest in treating local issues (Mertens 2013; Yen-Kohl and The Newtown Florist Club Writing Collective 2016).

Community-based participatory research focuses on fostering community participation through the maintenance of partnerships, having partners and stakeholders be an active and integrated part of the research process, and producing work that can support context-specific solutions (Arias 2015; Pham 2016). Thus, CBPR is inherently founded on practices of co-creation and power sharing. My community partners and I began working in 2017, and they remained my primary affiliates on this 2019-2020 project and participated in the research design, proposal development, participant recruitment, problem solving, data collection, and creation of informational materials, such as infographics and other explanatory material of this study's results given to participants and the town office. Using CBPR created mutual trust and understanding between me and my partners, residents who interacted with the community partners, and other residents and stakeholders in the community (Rosengren et al. 2014). Trust, transparency, and understanding were supported through frequent and regular meetings before, during, and after completing this study, discussing disagreements, and coming to united decisions on how to resolve disagreements. Secondly, opinions, insights, and ideas of community partners were treated as valuable and valid knowledge, rather than secondary to expert knowledge. As a result, CBPR legitimates knowledge undervalued or ignored in traditional research approaches. Especially in Japan, where non-expert knowledge is treated as inferior, illegitimate, and belittled by policy makers, government officials and researchers, CBPR supports the pursuit of co-producing knowledge, equity, and justice in research by de-centralizing the hegemony of these expert knowledge (Ivankova 2015).

Lastly, working jointly helped identify which methods would be most receptive to residents, and what issues were most important. For example, a focus on depopulation and industry decline was specified by partners and residents, and therefore these were included in the review of social and economic conditions in the community. Social capital became the theoretical vehicle by which to examine issues such as these when reviewing reconstruction effects on recovery outcomes. Additionally, 3 outreach programs to address resident needs were co-implemented with the research (not focused on in this paper). As such, CBPR helped create a research design that centered using research to serve the community immediately and directly.

\section{Materials and Methods}

\subsection{Research Objective and Design}

The first objective of this study was to provide insight into how social capital acts as an asset to address social and economic issues in Minamisanriku by examining social capital differences across gender, age, location, relationships, and strong and weak ties. This objective was accomplished using social capital mapping exercises $(n=200)$ that identified 
1994 relationships in the community, and a sub-sample of semi-structured interviews of mapping participants $(n=70)$. The interviews were used to meet the second objective, which was to assess the extent of resident social capital driving economic growth, recovery, collaboration, and decision making. These primary methods were complemented by participant observation at community events, with project partners, and other community organizations. Additionally, participant observation was used when volunteering with farmers, fishers, schools, elderly care homes, and other groups in the community. Secondary data in the form of town documents and reconstruction reports were used to investigate reconstruction issues, discussed later in Section 4.

\subsubsection{Social Capital Mapping}

The mapping exercises were created as a way for residents to conceptualize and document their social capital and included demographic data, such as age, gender, and location of participants, and the age, gender, location, relationship type, and relationship strength of the individuals in their social network (the mapping instrument is provided in Appendix A, see Figure A1). Participants were asked to consider people they trust and to write down the first ten people who came to mind. The classification of high and weak trust was determined by how close individuals were placed to the center of their map (e.g., high/strong) and the outer of their map (e.g., low/weak). Additionally, participants were asked to consider whether they believed any of the individuals on their map were an authority or high-status individual with decision-making influence at the neighborhood, district, or town level. This classification determined the amount of linking capital a participant possessed. The age, gender, location, relationship type (i.e., familial, acquaintance, etc.), and relationship strength of individuals determined whether a relationship represented bonding social capital or bridging social capital.

Mapping exercise participants were recruited through the efforts of eight community partners, including a non-profit organization, a farming collective, an educational center, a sustainability center, a farming business, a fishery collective, a business association, and a mothers group. Partners provided informational flyers to potential participants and disseminated meeting information. Mapping exercises were completed during group sessions, with an average of 20-30 individuals in attendance. Four group sessions were held before social distancing was mandated due to COVID-19. The remaining mapping exercises were completed remotely, via mail, but the recruitment process remained the same.

\subsubsection{Interviews}

The social capital mapping exercises were a vehicle to recruit interviewees as only having data on the amount social capital would not adequately explain its effects in the community, how it is used, or whether types of social capital, such as linking capital, are used in ways that are conducive to positive recovery, effective decision making, and collaboration. Potential interviewees were approached during the mapping group sessions if they had identified at least 2 influential individuals on their map. Once social distancing due to COVID-19 was mandated, maps returned by participants in the mail were sent a follow up if they met this criterion. In total, 70 semi-structured interviews, averaging between 30 and $90 \mathrm{~min}$, were held either in a location of the participant's choice or over a video call. All interviews were recorded and transcribed. All interviewees were given pseudonyms. Interviewees were asked a set of decision-making and influence questions focused on their capabilities based on the linking capital they possessed. This included a total of 12 questions focused on their perceptions of their influence, other's influence, belief in their ability to work collaboratively with others, and their satisfaction with their level of decision-making power at the neighborhood, district, and town levels. The second set of 3 questions focused on their opinion of and experiences with town development, and what sort of programs they would like to see in the community, what they believe 
community needs are, and what needs they would like the government to address (both sets of interview questions are provided in Appendix B).

\subsubsection{Participant Observation}

Participant observation was used to help qualify the general interactions between groups in the community, to understand barriers and difficulties affecting community members, and to understand how groups overcame difficulties in their daily lives. This information was important in determining particularly vulnerable groups, assessing their needs, and identifying possible solutions to the problems they face with my partners.

\subsubsection{Secondary Data}

Secondary data and material were collected from yearly Minamisanriku Town Statistical Reports (2005-2020), Agriculture and Forestry Censuses and Fishery Censuses from the Ministry of Agriculture, Forestry and Fisheries (2005, 2008, 2010, 2013, 2015, 2018, 2020), Minamisanriku Town Office (2011) Resident Intention Survey and Minamisanriku Town Office (2012) Earthquake Reconstruction Plan. Information from Minamisanriku and the census was used to frame a discussion on the town's past and present social and economic conditions. Disaster-related materials were used to examine reconstruction planning in the community and its affects with consideration for how government actions may influence the status of social capital and the ability of residents to use social capital as an asset.

\subsection{Analytical Methods}

The analysis of this study is comprised of three stages. First, secondary data were used to create various descriptive statistics of the town's social and economic conditions (i.e., household and population changes, economic changes, etc.) from 2005 to 2020. A review of local government disaster documents was used to construct an outline of Minamisanriku's reconstruction process, such as which projects were selected for development, resident's wants and needs, and outcomes of the planning process. This review of Minamisanriku is provided in Section 4, followed by results in Section 5.

Second, mapping exercises were hand coded for bonding, bridging, and linking social capital. Bonding social capital was determined by relationship type (e.g., family, friend, or coworker) and the trust/strength of the relationship (e.g., strong or weak tie). Bridging social capital was determined by relationship type (e.g., previous coworker, acquaintance, other), trust/strength of the relationship, and by how different the participant was from the individual in terms of age, gender, and location. For example, a female, 30-year-old participant living in Shizugawa who has a previous working relationship with a 50-year-old male living outside of town would be categorized as a bridging relationship due to the considerable differences between them. Descriptive statistics of participant demographics and relationship information are provided in Section 5.1.

Third, interviews were transcribed in their original language and coded line by line to create a selection of in vivo codes or categories based on the wording used by participants to explain their influence, satisfaction, decision-making and collaborative capabilities. For the first set of questions, these in vivo codes were grouped into 2 main codes, decision making and collaboration. Under these main codes, there were groupings of subcategories. This included "one's place," "one's role," "navigating power," and "accessing information" for decision making, and "from within district" and "not between districts" for collaboration. For the second set of questions on town development, there were 3 main codes, "responsibility," "social infrastructure," and "economic infrastructure." The description of these codes is discussed in Section 5.4.

\section{Minamisanriku-Reconstruction and Social Capital}

On the afternoon of 11 March 2011, Minamisanriku faced a tsunami more than 40 feet high (peaking in some areas at 60 feet). The tsunami killed 620 residents, with an additional 211 still missing. Across its four districts, three were completely devastated. Togura, 
Shizugawa, and Utatsu comprise the coastal districts, with most homes and businesses located close to the coast (see Figure 1). Of the homes that survived the tsunami, 91 percent in Togura, 86 percent in Shizugawa, and 76 percent in Utatsu were damaged by the earthquake. Further, 84 percent in Togura, 88 percent in Shizugawa, and 78 percent of homes in Utatsu were destroyed (Minamisanriku Town Office 2011). The district to receive the least damage, Iriya, only lost 9 percent of all homes, and 30 percent of surviving homes were damaged by the earthquake. Approximately 63 percent of all households were destroyed in the tsunami (3321). The day after, 9753 people were immediately homeless. Families were placed into 58 shelters and temporary housing complexes, 6 of which were located outside the town (Minamisanriku Town Office 2012).

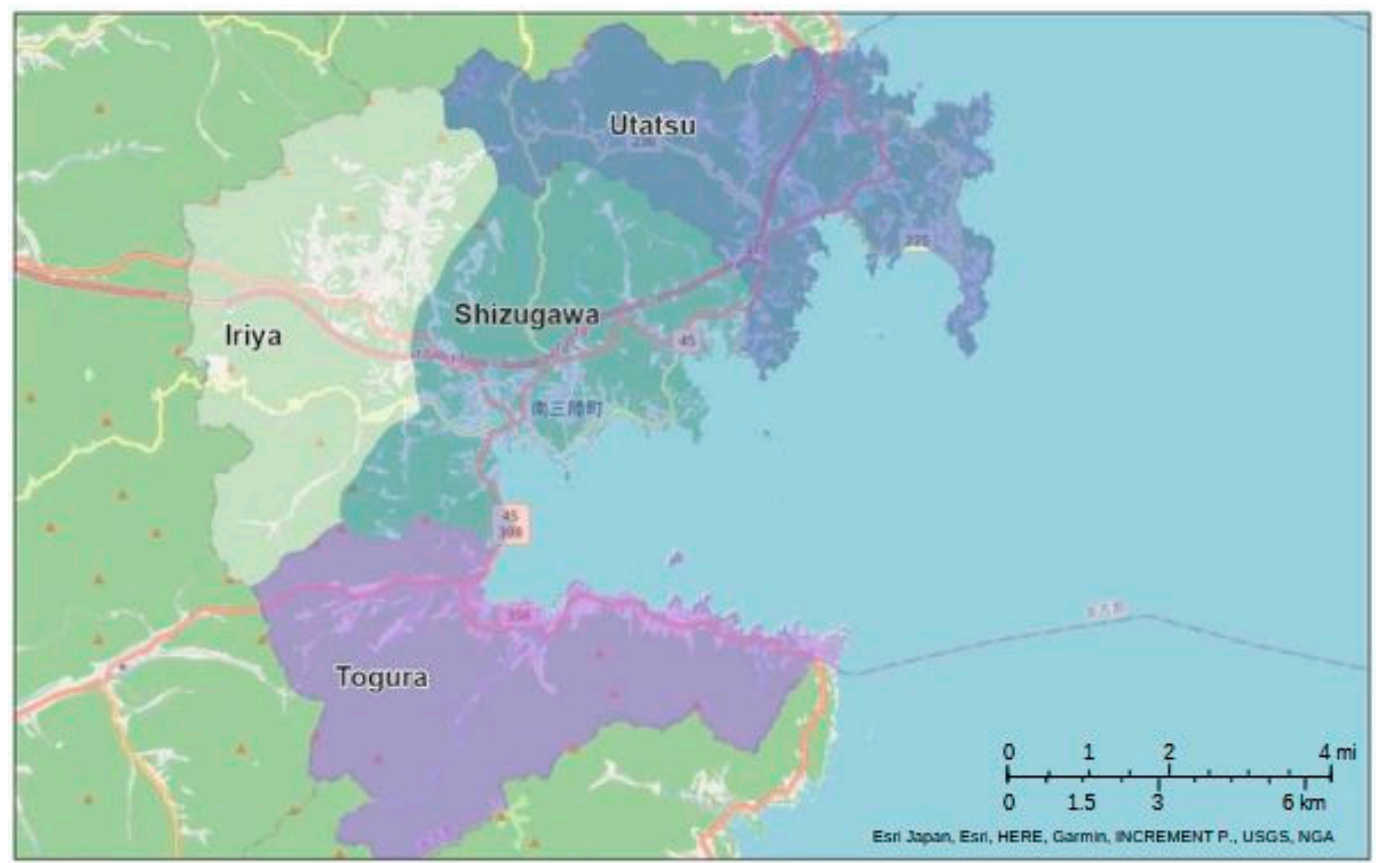

Figure 1. Map of Minamisanriku by district. Source: Adapted from Esri (2020), Cho Cho Moku, Japan Boundaries (basemap).

\subsection{Reconstruction Planning and Development}

The local government held three different meetings to develop a reconstruction and town redevelopment plan. These included the Minamisanriku Earthquake Reconstruction Planning Conference, which was mainly fielded by a panel of technocratic experts, and two supplemental meetings, one of which included a townspeople conference. From 1 to 15 July 2011, the town office surveyed the main concerns of residents, and what they would like included in the plans. In total, 3469 residents completed the survey but disproportionately included men (2691) to women (728). Additionally, 77 percent of participants were over the age of 50, with 60-year-olds comprising 28 percent of the total. At the time of the survey, 35 percent of individuals were living in a similar location to pre-disaster, 25 percent were in temporary housing, followed by 15 percent in shelters, and 12 percent in rentals (Minamisanriku Town Office 2011).

Of concern to residents was that they wanted to live in an area safe from future tsunamis by relocating to high ground ( 63 percent), in a place close to hospitals and other welfare/health facilities (43 percent), and somewhere close to shops (33 percent) (Minamisanriku Town Office 2011). Residents could choose from multiple options on questions regarding both living situations and where they believed buildings should be constructed. In total, 68 percent wanted to relocate housing to high ground and 58 percent wanted schools, hospitals, and government buildings placed on high ground. Importantly, only 24 percent supported the building of a seawall. Additionally, a majority wanted strong welfare and health infrastructure ( 66 percent), followed by fisheries ( 40 percent), 
and housing (40 percent) to be the focus of reconstruction planning. (Minamisanriku Town Office 2011).

Following this survey and the three conferences, a reconstruction plan was created in December 2011 and was finalized in April 2012 (Minamisanriku Town Office 2012). However, despite the intentions outlined in the survey, the developed plan differed significantly regarding safety measures.

The government provided three different safety measures to consider. These included relocation to higher areas, artificially raising an area's sea level by land filling, and the construction of seawalls. In the case of Minamisanriku, there was a super majority for relocation over the construction of seawalls, and land filling was not discussed. However, in the reconstruction plan, instead of pursuing one safety measure, the local government pursued relocation, land filling (up to 30 feet in height), and seawall construction. However, seawall construction had a stipulation that residents could occupy their original land. Despite this, Minamisanriku's reconstruction plan did not build new homes in original locations and allowed only industry and businesses to be built in low-land areas (if funded by the local government). This meant that individuals with houses damaged by the earthquake but in a location where a 6 foot tsunami was possible, were entirely responsible for reconstruction costs. Additionally, special local government housing assistance excluded elderly and low-income individuals and families (Kaneko 2017). Thus, there were differences in who was eligible for government-sponsored relocation.

These differences arose primarily due to how post-disaster recovery in Japan is regulated, which often ignores the rights of disaster victims over spatial planning, construction, and public infrastructure (Kaneko 2017). In the case of Minamisanriku (and other communities), recovery planning was much more government centered, meaning that recovery plans were decided by the head official (e.g., mayor) with minimal requirements for involving residents. Secondly, decisions remained relatively private from the individuals and communities they would affect, with relocations and land readjustments often confirmed behind closed doors. As a result, once plans were in implementation stages, reconstruction was often delayed due to conflict and disagreements (Kaneko 2017).

Similarly, the disaster policy and legislation prior to 2011 did not provide municipalities guidance on disaster recovery nor reconstruction (Shinoyama 2013). Moreover, policies guiding disaster management reinforced that local municipalities and disaster victims should be primarily responsible regarding recovery and reconstruction despite them having very little resources, training, or autonomy to do so (see Ota 2019 for a longer discussion on issues with current disaster policy and laws). These bureaucratic and governance issues, along with reconstruction planning, created entrenched problems in the community. Primarily, despite residents specifying wanting to live in a safe location with access to health services, and shopping, the only district to achieve this is Shizugawa.

Especially in Togura, neighborhoods are now isolated from each other, with minimal access to resources due to being built far from amenities. Mobility of the towns' residents across districts is a major issue, especially to those without reliable transportation, such as the elderly. Mobility is such a major concern that multiple organizations are studying ways to support the micro-mobility of residents (e.g., electric scooters). The mobility issue arose after the local government decided to not rebuild the train line due to prohibitive costs, and instead opted for a busing system, subsidized by Japan Railways (JR), a major railway company in Eastern Japan. However, the bus line is inconvenient, with limited drop-off locations, and does not go far into districts outside Shizugawa. While the Tohoku Expressway from Ishinomaki (southern neighboring city) was extended through Minamisanriku to Kesennuma (northern neighboring city), Togura is far from this expressway. Additionally, rather than increasing tourism, the tourism association head noted that before the expressway was completed, travelers would have to go through Minamisanriku but now with the connection complete, travelers stop into Minamisanriku less, granted the expressway made travel between towns and cities much more convenient. Additionally, the expressway has a 
major exit close to Shizugawa's tourism hub, whereas the exit in Utatsu is farther removed from their tourism facilities.

Most redevelopment projects focused on Shizugawa, making it a central hub for daily necessities including, grocery shopping, banking, postal services, and health services among others. As a result, the Utatsu, Iriya, and Togura districts are underdeveloped, with little in the way of social or economic resources. Due to lopsided redevelopment, it has become more difficult for districts such as Togura to survive, where there is not a single grocery store, convenience store, or market.

Between 2011 and 2017, of the 18 major reconstruction milestones, 14 were completed in Shizugawa, 2 in Togura, and 2 in Utatsu (Minamisanriku Town Office 2017). In Togura, the elementary school was reopened in 2015, and the community center was completed in 2016. In Utatsu, the Isatomae Fukko Shopping Street was created in 2011, and then replaced in 2017 with the Hamare Market. Overall, the number of reconstruction projects that support satisfactory lifestyles and livelihoods in Utatsu, Iriya, and Togura is insufficient. Especially for social infrastructure, Togura lacks health services, public spaces such as parks, community centers, and other educational services, such as a library, after-school activities, or tutoring. While the community does have a Marine Center (a museum and ocean educational center), there are no other educational resources except the elementary school. In terms of public spaces for sports and recreation, the Kamiwarizaki Campsite is primarily used by tourists and there are no other large parks available to residents. Iriya also lacks health services and educational services but does have a large facility (Hikoro no Sato) where community events are often held. Due to Utatsu's proximity to Shizugawa, residents have close access to health services depending on which neighborhood they live in, and educational services in Utatsu are well developed, but public spaces are lacking, and the only major facility available for large events is Heisei no Mori. However, Heisei no Mori primarily acts as lodging for tourists, with a hotel and restaurant on site. As a result, there are not many public spaces available to residents whose primary function is not tourism.

\subsection{Changes to Community}

Along with reconstruction issues, the town of Minamisanriku also has internal conflicts due to mergers issued by the prefectural government. In 2005, a merger between Shizugawa and Utatsu was finalized, with the mayor of Utatsu stepping down and the incumbent mayor of Shizugawa, Jin Sato, becoming the mayor of Minamisanriku. As a result, Minamisanriku had only existed 6 years before the disaster. The merger frequently appears when discussing town identity, especially for older to middle-aged residents compared to their younger counterparts. Residents in their late 30s and older tend to strongly identify with their district as their "community" whereas much younger members of the community identify with Minamisanriku (Ward 2018). Similarly, the stratification among different generations in the town is also present between the districts of Utatsu and Shizugawa, with Utatsu often being treated as the younger, less successful sibling of Shizugawa (Ward 2018). Due to these differences, the community narrative in the town is not unified, with residents often proposing a smaller conceptualization than the town office.

These different community conceptualizations and narratives are common in disaster communities that are especially disenfranchised or where governance structures are largely centralized (Tierney 2019; Shiraishi and Matoba 2019; Shaw 2014; James and Paton 2016). This is especially problematic when the geographical community is destroyed, greatly affecting community members sense of place, their agency, their ties (i.e., social, cultural, and emotional), and collective identity or purpose (Campbell 2000; Blackwell and Colmenar 2000; Israel et al. 2012; Aldrich and Meyer 2015). Often in cases of major catastrophe, community members will exhibit very strong collaboration and collective action due to the overwhelming lack of resources and the need to rely on others for social, economic, physical, and emotional support (James and Paton 2016; Yamamura 2010). This group 
action has been documented in Minamisanriku previously (Goulding et al. 2018; Yotsui et al. 2016), but in the long term, these connections have weakened due to depopulation and other conflicts (Ward 2018; Littlejohn 2017; Cheek 2020).

The difficulties of Minamisanriku becoming a unified community are reflected in how each district has been treated during the reconstruction process. These difficulties are visible in the political and inter-district conflicts that continually plague town relations. While in the field, disagreements were primarily due to reconstruction planning and views of negligence, with a variety of wrongful death lawsuits lodged against the mayor. Similarly, disagreements between the town office and Hotel Kanyo, the primary hotel in town, lead to a lawsuit that was still on-going as of 2020. Other notable conflicts recorded while in the field include disagreements between the tourism association and Hotel Kanyo, with some individuals very unwelcome at meetings or not invited at all, on-going disagreements on who is responsible for the creation of kira-kira uni-don (sparkling sea-urchin rice bowl) used in tourism advertising, and on-going issues between fishers in Togura, Utatsu, and Shizugawa, related to support and subsidies (see Sekine and Bonanno 2016 for further discussion on subsidies and reconstruction related to fisheries). Otherwise, there remains discontent between groups and the town office due to the local government not properly addressing seawall questions, concerns, and confusion, as well as the legacy of poor to little resident involvement and participation on committees or other decision boards that affect their districts (Ward 2018; Littlejohn 2017; Cheek 2020; Fraser et al. 2021).

\subsection{Changes to Population and Households}

Since the disaster, depopulation has accelerated, with the town population down 30 percent from pre-disaster levels. Total households have declined rapidly in Shizugawa as well, with many neighborhoods becoming less dense and the number of neighborhoods with less than 25 households becoming more common (see Figure 2).

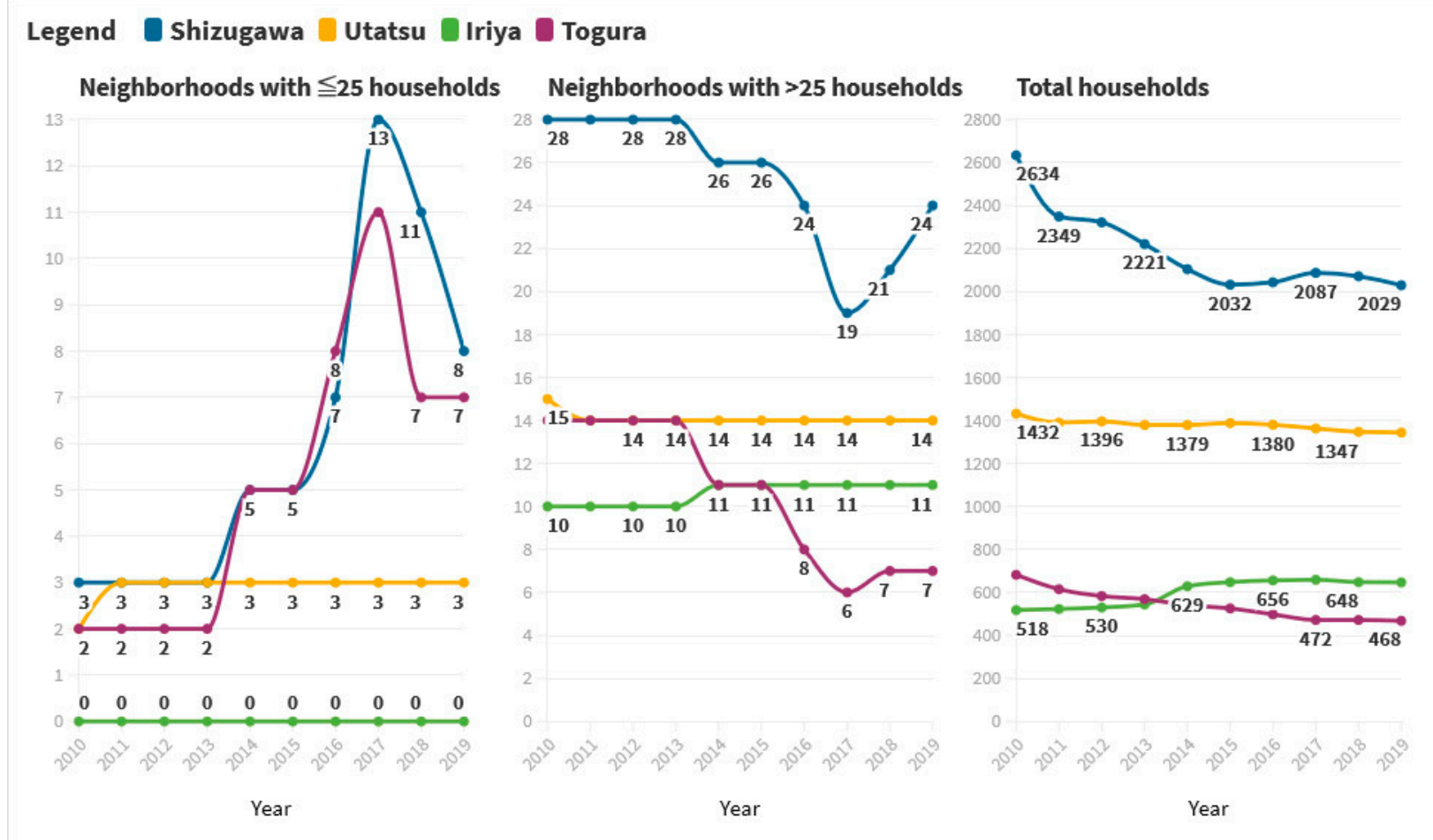

Figure 2. Changes in neighborhood households by district, 2013-2019. Source: Minamisanriku Town Office (2010, 2015, 2020).

Collectively, since 2010, there are 711 fewer households, falling from 5199 to 4488 . There is high volatility in households, due to the constant movement between neighbor- 
hoods, construction of new neighborhoods, and mergers. In terms of total households, declining numbers have slowed, but in contrast, the total population of the town is in rapid decline. Between 2010 and 2019, the population fell from 17,060 to 12,564, with an average loss of 300 individuals a year and a total loss of 4496 individuals. As a result, while the number of registered households in the community is stabilizing, the number of people living within households is less dense.

\subsection{Economic Changes}

Before the disaster, the primary sector was in decline (e.g., agriculture, fisheries, forestry). However, like household changes, industrial decline has accelerated since 2011 (see Figure 3). Most redevelopment funding was placed into building new marine processing plants, ports, and rehabilitating fisheries, which was in line with resident responses from the intention survey (Minamisanriku Town Office 2012). The effects of this spending are observable, with fishery businesses increasing. However, the number of fishers continues to decline.

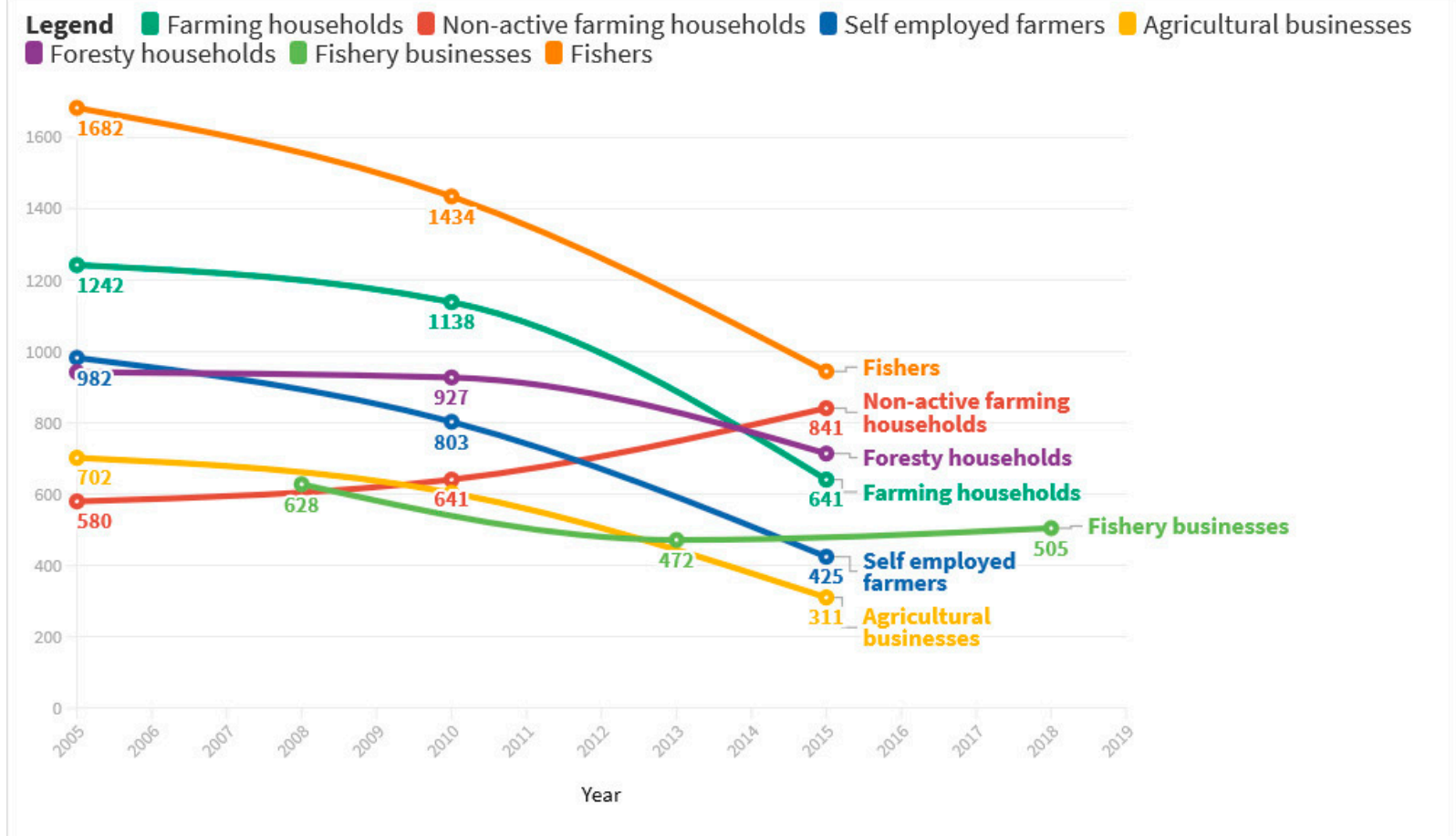

Figure 3. Changes to agriculture, fishery, and forestry businesses, households, and employment, 2005-2019. Source: Minamisanriku Town Statistics, 2006-2020; Ministry of Agriculture, Forestry, and Fisheries Fishery Census Data, 2008-2018; Agriculture and Forestry Census Data, 2005-2020.

All other primary sector industries have had less success. Similar redevelopment funding was not spent on remediating farmland or funding forestry infrastructure, despite Iriya requesting assistance. Additionally, the ports built in Togura and Utatsu are much smaller than the port in Shizugawa. As a result, recovery of fishers across districts is very unequal, and there are inequities across items such as ship ownership, access to recovery funding, and other sources of support. As an example, the 96 fishers in the Togura district formed a single cooperative through the Ganbaru Fishery Reconstruction Support Project and crowdfunded through their cooperative. Of these 96,38 went on to create a separate Oyster Fishery Union to protect their livelihoods. Similarly, Utatsu fishers had to find support elsewhere, by applying to disaster recovery grants, of which all fishers were covered. 


\subsection{Implications for This Study}

Current reconstruction projects, especially regarding safety measures and industry support, have created inequitable recovery trajectories for the districts of Togura, Utatsu, and Iriya. The lack of aid from the local and national government prompted fishers to find support elsewhere, but of those in this situation, Togura was the only district that exhibited effective collective action to mitigate adverse effects of the disaster. However, this was performed at the expense of collaborating with fishers in Shizugawa and Utatsu, leaving the district largely isolated.

Similarly, historical issues due to the town merger in 2005 and general issues with disaster management and policy affect districts' and the town's ability to handle conflicts. Differences between town office representation of Minamisanriku as a unified whole, and district experiences of having to act independently creates discontent between districts, but also between the town office and other key stakeholders and groups in the town.

Based on the status of Minamisanriku, and how social capital tends to operate in post-disaster communities where there are large structural inequalities, the distribution of social capital may be uneven across districts. Secondly, the quality of social capital may be less robust and less diverse in underdeveloped districts, since there is less social infrastructure and travel between them as a direct result of reconstruction. For linking capital, as Shizugawa is the most developed district, they may likely retain much of the available linking capital in the town and Iriya, Togura, and Utatsu residents may have less linking capital.

\section{Results}

\subsection{Demographic Characteristics of Mapping Participants}

The demographic profile of the 200 participants in this study is as follows: 109 were female $(54.5 \%)$ and 91 were male $(44.5 \%)$. The age range was $20-80$, with $121(60.5 \%)$ between 20 and 40 and $79(39.5 \%)$ between 50 and 80 . The largest group was 40-year-olds at $55(27.5 \%)$, followed by 50 -year-olds at $43(21.5 \%)$, and 30 -year-olds at $40(20 \%)$. In terms of district, 36 were from Togura (18\%), 48 from Iriya (24\%), 44 from Utatsu (22\%), and 72 from Shizugawa (36\%). Descriptive statistics of participant demographic data are available in Table 1.

Table 1. Descriptive statistics.

\begin{tabular}{|c|c|c|c|c|}
\hline \multicolumn{5}{|c|}{ Descriptive Statistics of Participants $(n=200)$} \\
\hline Variable & Mean & Standard Deviation & Mode & Range \\
\hline Gender & 0.46 & 0.49 & Female & 0 (female) to 1 (male) \\
\hline District & 1.76 & 1.11 & Shizugawa & $\begin{array}{l}0 \text { (Togura) to } 3 \\
\text { (Shizugawa) }\end{array}$ \\
\hline Age & 42 & 14 & 40 & 20 to 80 \\
\hline \multicolumn{5}{|c|}{ Descriptive statistics of relationships $(n=1994)$} \\
\hline Gender & 0.54 & 0.49 & Male & 0 (female) to 1 (male) \\
\hline District & 2.34 & 1.48 & Shizugawa & $\begin{array}{c}0 \text { (outside) to } 4 \\
\text { (Shizugawa) }\end{array}$ \\
\hline Age & 44 & 15.12 & 40 & 10 to 90 \\
\hline Relationship & 2.82 & 1.63 & Acquaintance & 0 (other) to 5 (family) \\
\hline TieStrength & 0.69 & 0.46 & Strong & 0 (weak) to 1 (strong) \\
\hline SocialCapital & 0.89 & 0.87 & Bonding & 0 (bonding) to 2 (linking) \\
\hline
\end{tabular}

The demographic profile of the 1994 participant relationships in this study is as follows: 906 were female $(45 \%)$ and 1088 were male (55\%). The age range was 10-90, with 1041 between 10 and $40(52 \%)$, and 953 between 50 and 90 (48\%). In terms of district, 264 were from Togura (13\%), 361 from Iriya (18\%), 375 from Utatsu (19\%), 641 from Shizugawa $(32 \%)$, and 353 from outside the town (18\%). In terms of ties, 613 were weak $(31 \%)$ and 1381 were strong $(69 \%)$. In terms of social capital, 878 characterized bonding $(44 \%), 446$ 
as bridging (22\%), and 670 as linking (34\%). Lastly, of the relationship types, there were 5 distinct groups, familial relationships at $387(19 \%)$, friendships at $500(25 \%)$, co-workers at $283(14 \%)$, previous co-workers at $77(4 \%)$, acquaintances at $697(35 \%)$, and other at $50(3 \%)$. Descriptive statistics of relationship demographic data are available in Table 1.

\subsection{Cross-Tabulation of Participant District by Relation's Gender, Tie Strength, Relationship, and Social Capital}

A cross-tabulation was performed to see patterns between participant districts, and their relation's gender, tie strength, relationship type, district, and social capital. As expected from the history of development in Minamisanriku, Shizugawa holds the most linking capital and the largest proportion of strong ties. Secondly, social capital distribution is affected by gender, with more men than women retaining it, affirming that there are inequities with social capital present in the town, especially in Iriya, Togura, and Utatsu. Unexpectedly, Utatsu has less linking capital than Iriya. Additionally, Iriya has the second-highest proportion of strong ties (see Table 2). As expected, Togura has the lowest proportion of strong ties and linking capital.

Table 2. Cross-tabulation of participant's district by relation's gender, district, tie strength, relationship type, and social capital $(n=1994)$.

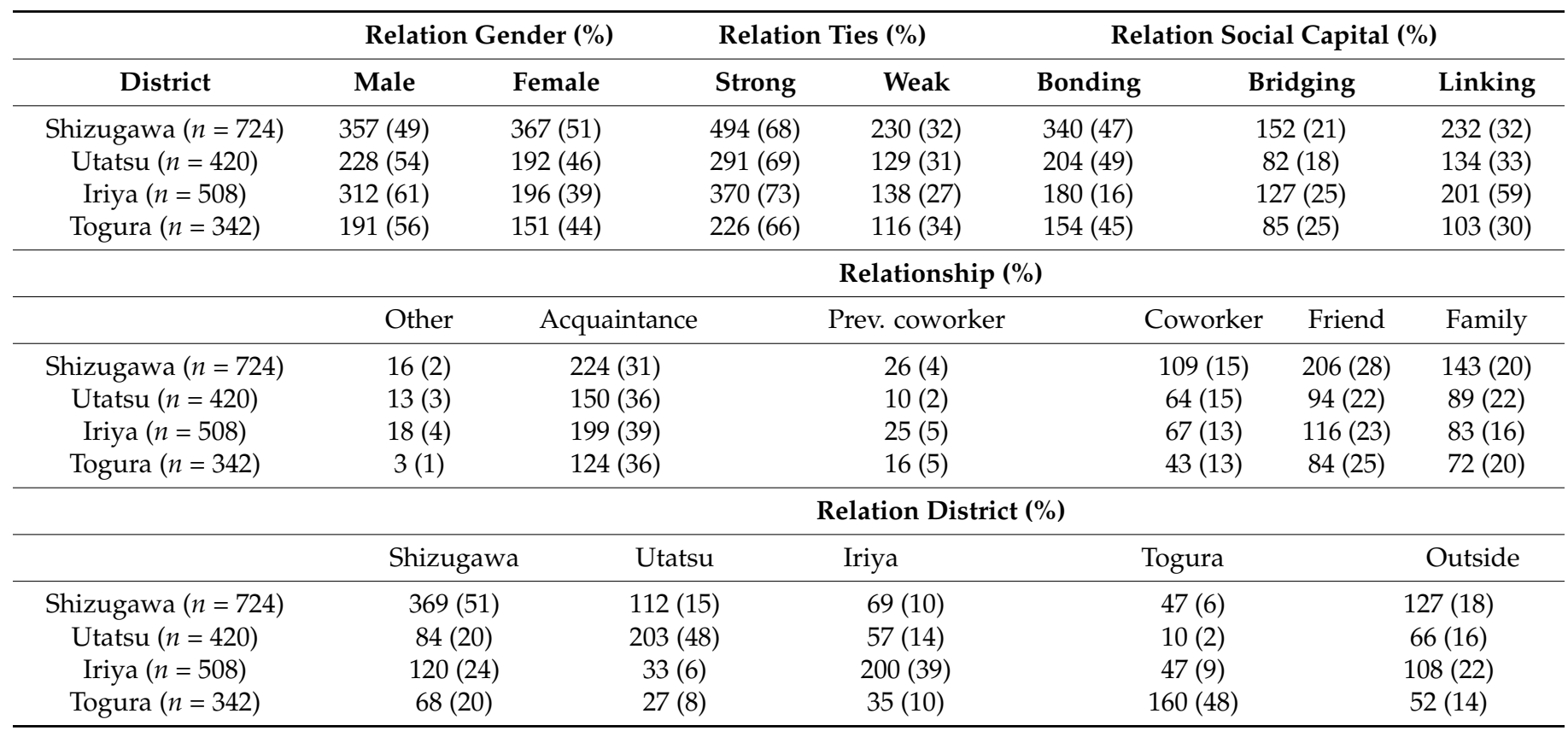

Note: percentages are listed across rows in parentheses.

In addition, there are large differences across genders. Most linking social capital is retained by men, with gender dynamics often favoring women linking to men, rather than men to women (see Figure 4). In total, 228 linking relationships within districts connect to men, with 157 between men only. In comparison, only 130 connect to women, with 78 between women only. Of the districts, Iriya has the highest amount of male-to-male linking relationships, followed by Shizugawa, Togura, and Utatsu.

Similarly, when looking at gender dynamics across districts, including outside relationships, male to male linking relationships still comprise the greatest proportion (145), followed by female to male (73), female to female (63), and male to female (31) (see Figure 5). As a result, across districts as with within districts, males retain the most linking capital, with the total for male linking relationships being 446 out of the total of 670 linking relationships. Further, Iriya has the most linking relationships with Shizugawa and those living outside the town, meaning that Iriya is more strongly connected to outside individuals with linking capital than it is with those in Utatsu or Togura (see Figure 5). Similarly, Shizugawa 
has more linking ties to outside individuals than it does with individuals in Togura. Thus, out of all districts, Togura lacks the most connections to linking capital throughout the town and also has very inequitable distributions of linking capital across gender as well.

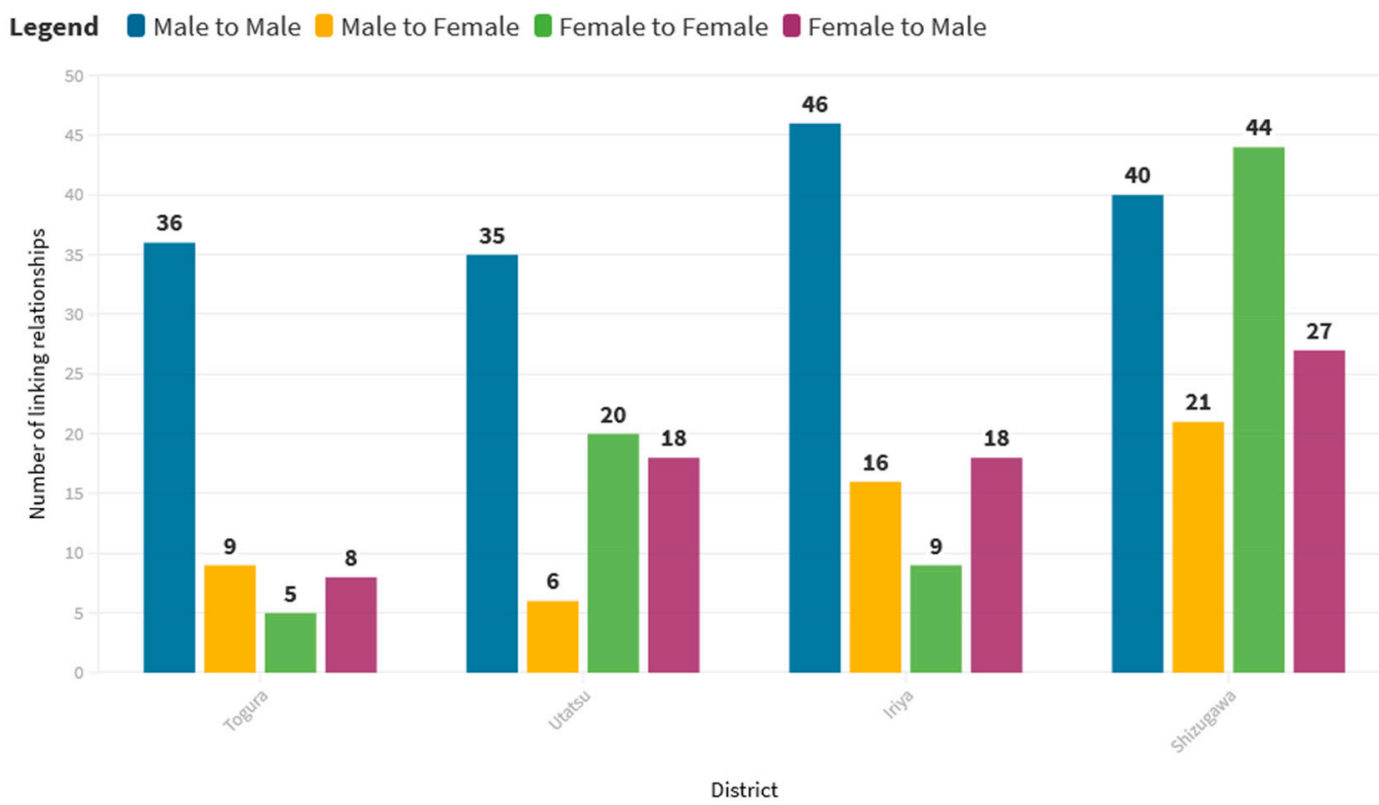

Figure 4. Differences in the total of male and female linking relationships within districts from smallest quantity to largest quantity $(n=358)$.

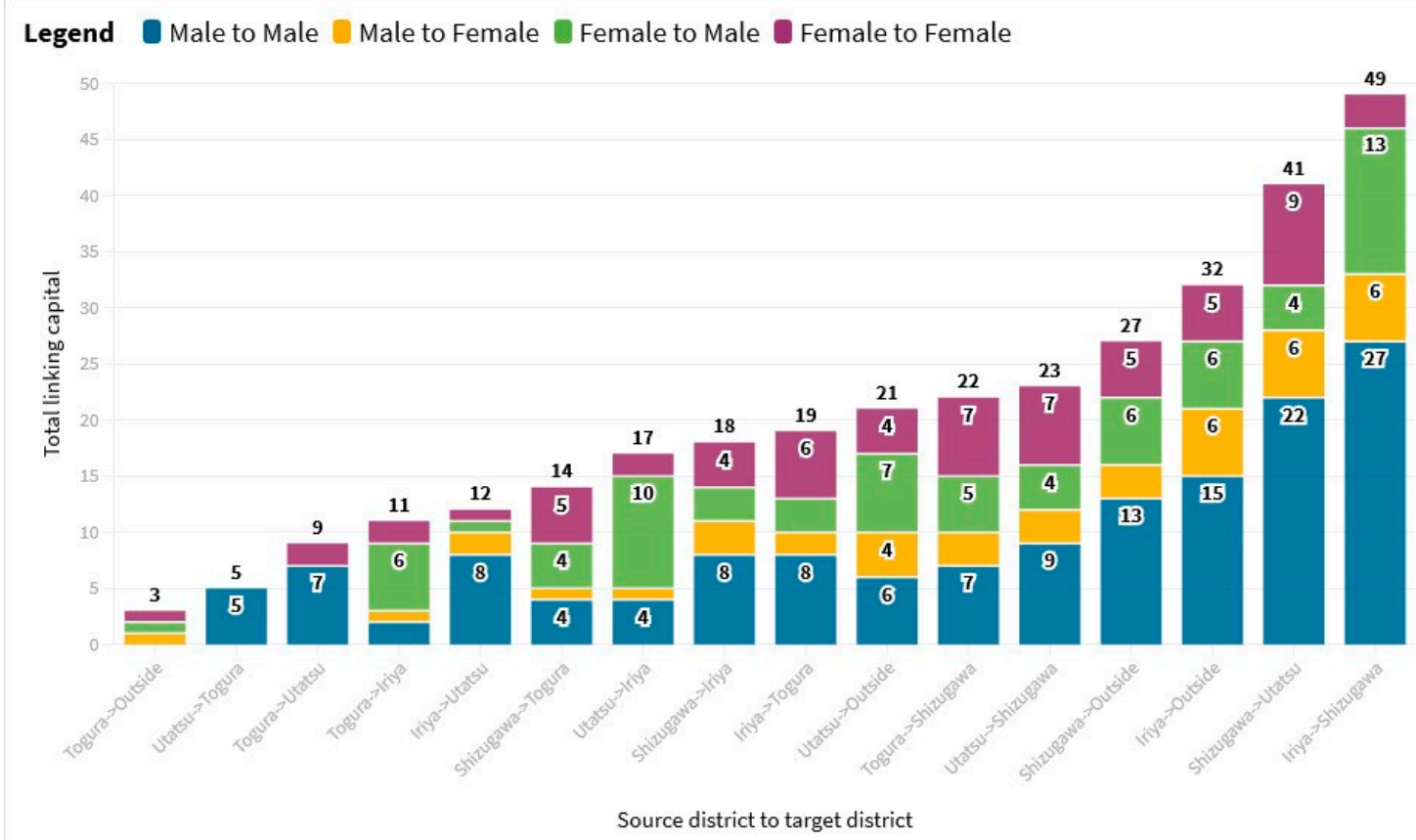

Figure 5. Differences in the total of male and female linking relationships across districts from smallest quantity to largest quantity $(n=312)$.

5.3. Directional Relationship between Participant District, Relation District, and Linking Capital

A directional graph of linking relationships by district between participants and their relations is provided in Figure 6. The size of the group is equal to the total number of relationships between groups. For example, "Utatsu (Participants)" is sized according to the number of participants from that district $(n=44)$, whereas "Utatsu (Linking)" is 
sized by the number of relationships participants had across districts that connected to an individual in Utatsu who they noted is either influential, has authority, or has high status. Therefore, this figure shows the collective linking relationships across districts. The "Outside" group is comprised of individuals with which participants have a linking relationship, but that live either outside the town or in another prefecture.

Group Shizugawa [Particpants] Utatsu [Participants] Iriya [Participants] Togura [Participants] Shizugawa Linking Utatsu Linking Iriya Linking Togura Linking Outside Linking

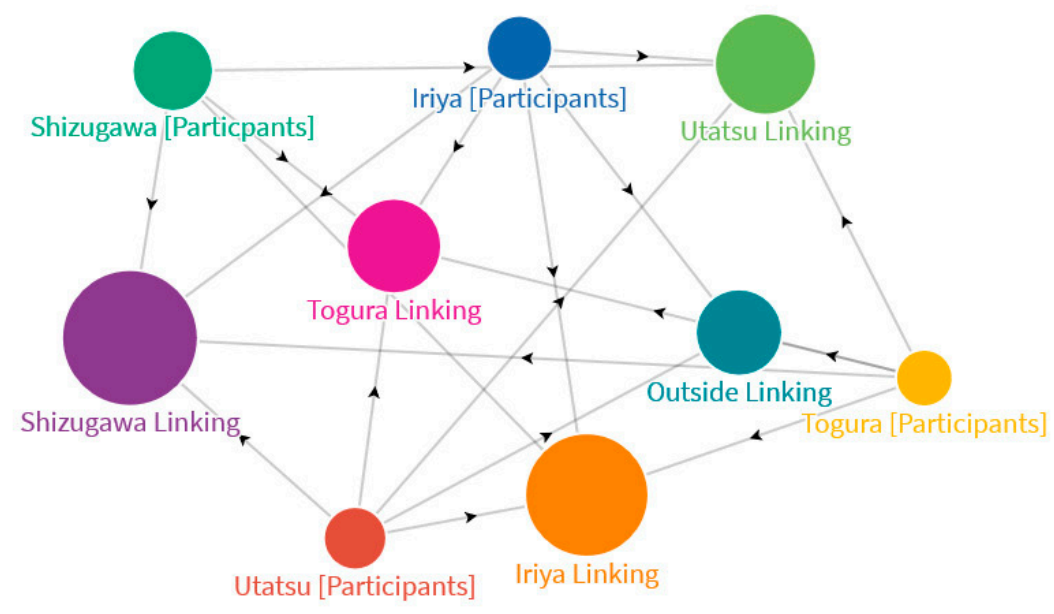

Figure 6. Distribution of linking capital by district ties $(n=670)$.

Notably, Shizugawa, Iriya, and Utatsu have more linking relationships outside the town than they do with individuals in Togura. In total, these districts have 38 linking relationships with an individual in Togura, out of the 103 identified in the district meaning that Togura is insulated from other districts. Across districts and all types of social capital, Shizugawa, Iriya, and Utatsu had very little association with Togura, suggesting that the isolation of Togura is much worse than first thought.

\subsection{Interviews on Decision Making and Town Development}

Results from the content analysis of the interviews illustrate barriers to the utility of linking capital. First, in responses to decision making and influence, respondents expressed that they felt misplaced and that it was not their role to make decisions. Secondly, their responses expressed inferiority to others with their knowledge or influence being secondary to that of others. Additionally, some expressed no interest in decision making or that they had not considered that their thoughts and opinions would matter for higherlevel decisions, such as at the town level. Finally, across responses, individuals accepted inequalities as normal. As such, linking capital as an asset to engage power structures and decision-making processes is limited. Especially, residents with some linking capital do not view it as "their role" or "their place" to involve themselves. Thus, while social capital disaster studies, such as Aldrich (2012a) and Shaw (2014), place social capital as bridging divides in decision making, cultural forces and social norms, such as "one's role" and "one's place," may mitigate attempts to participate. This phenomenon is discussed further in Section 6.1.

Next, responses to decision making and influence differed for individuals with five or more linking relationships. This group expressed the ability to influence decision making and was very knowledgeable about decision-making processes in the community. Notably, individuals in this category were already in positions of power, suggesting that select groups hold useable linking capital. Secondly, linking capital as an asset to navigate power structures and access information is limited when those with rich linking capital engage 
mainly with other highly linked individuals. As a result, information and power are held within these networks rather than dispersed.

In contrast, when those with rich linking capital frequently interact with regular everyday people, linking capital may provide these connections with access to information and power sharing. As a result, these two competing findings highlight that "accessing information" is unequal, and therefore residents may have difficulty "navigating power" as suggested by Gill (2014) and Shiraishi and Matoba (2019). This phenomenon is discussed further in Section 6.2.

Next, responses to decision making and collaboration indicated that collaboration appears much more robust in small groups than between groups or districts, similar to findings by Yamamura (2010); James and Paton (2016); and Inaba (2011). The frailty of cross-district collaboration is due to how reconstruction pushed districts to be selfdependent. Thus, social capital as an asset to mobilize groups to collectively handle adverse disaster consequences mainly acted as a way for participants in this study to bridge holes, inefficiencies, and inequalities generated by reconstruction processes. However, this created firm group dynamics that limit the capacity of residents to access resources outside their district and to address social and economic problems. As a result, interviewees did not discuss district relations as collaborating to solve town issues, such as depopulation and industrial decline, in a unified manner. Rather districts operate independently and sometimes compete against their best interests. This phenomenon is discussed further in Section 6.3.

Lastly, responses to town development, community needs and programs, and government assistance formed a narrative that reconstruction has not met the needs of residents. Rather structural holes and minimal aid contributes to deep disparities, primarily caused by a lack of social infrastructure, and in some cases, the combined effect of minimal social and economic infrastructure. This phenomenon is discussed further in Section 6.4.

Overall, there were 25 women and 45 men in the interview sample, with linking capital ranging from a frequency of 2 to 10. In addition, 24 interviewees came from Shizugawa, 20 from Iriya, 16 from Utatsu, and 10 from Togura. 60 interviewees had a frequency of linking social capital between 2 and 4, and 10 interviewees had a frequency between 5 and 10. Otherwise, interviewee responses discussed in Section 6.1 had a frequency of linking capital between 2 and 4 . Interviewee responses discussed in Section 6.2 had a frequency of linking capital between 5 and 10 .

\section{Discussion}

\subsection{Decision Making and Influence-One's Place and One's Role}

Due to the overall dissatisfaction with town development, the expectation was that interviewees would express an interest in decision making or would address the lack of resident decision making in the reconstruction process. However, cultural norms and expectations seem to be the primary barrier to engagement.

Findings from one's place and one's role suggest that social norms of hierarchy are important when an individual considers participating. Similarly, social norms of who should be in decision-making spaces (e.g., town officials, public servants, or experts) delegitimates the knowledge and ideas of residents. As such, cultural and social norms of bureaucratic spaces limit resident capacity to use linking capital as an asset to engage these higher decision-making structures. In this case, Sasaki et al. (2020) and Gill (2014) points about Japanese bureaucratic systems fostering negative behaviors and norms do influence individuals' confidence to engage. As a result, the disenfranchisement and exclusion of residents is an uncontested part of the reconstruction process.

Secondly, due to the combined nature of resident disempowerment and the social and economic problems they juggle with in their daily lives, some individuals may not have the time to utilize their linking capital at all. This phenomenon aligns with the social capital findings from the mapping exercise. For example, individuals with extremely rich linking capital were from Shizugawa and Iriya. Suggesting that participating members 
from Utatsu and Togura may be too disenfranchised to attempt participating in town-level decision processes or are too weighed down by other more personal and economic issues, as Portes (2014); Waldinger (1995); and Kaneko (2017) suggest.

\subsection{Decision Making and Influence-Navigating Power and Accessing Information}

The major difference between individuals in Section 6.1 and those in Section 6.2 is whether the person was a high-status individual. For example, these individuals hold positions of power in the community, as an organization or association head, a town council member, a board of education member, a community leader, or as a leader of farmers or fishers. Additionally, this group participates in discussions about town issues, resident well-being, and other concerns frequently. However, after reviewing their maps together, it became clear that most of their linking relationships were with people in similar positions of power.

As a result, five interviewees kept most of their decision-making discussions within the workplace (e.g., town office and association). In contrast, the other five noted that they often interact with groups and individuals they have power over. This dynamic has two significant consequences. First, the chance of residents having access to power and information depends on whether their relationship is with someone who engages the public. Second, the access to knowledge of power structures and information is ununiform, and some have more access than others. This dynamic creates a space wherein residents may not understand how decision making occurs in the town and disengage from navigating these systems when needing assistance, help, or other aid. Examples of these consequences are discussed below.

As for consequences of navigating power and accessing information, insights from this group clarify conflicts between residents and reconstruction planning. For example, in town development discussions with Abe, there is confusion about the shared responsibility between the town office and the tourism association.

Ward: When I've spoken with other residents, many complain that there is not enough resident-focused projects, such as building public baths, parks, and other amenities for them to enjoy. Why do you think the local government hasn't created more resident-centered projects?

Abe: (head nodding) Yes, that was an issue back in (pause) 2014. I can't remember the name of it, but a lot of those things are supposed to be built now. I think most residents don't know that the local government shares decision-making with the tourism association, so (pauses) ... well, there was just more concern for recovery of the business district I think ... both groups have equal input on town development projects because most funding isn't controlled by the local government but by the tourism association ... Most subsidies come to us as economic grants, but I believe the majority are designated for tourism development.

Ward: So, what I'm trying to understand, is that residents don't understand why the town office supports other projects, but you mean that residents aren't aware of the tourism association's role on deciding projects? Sorry, I am just trying to clarify.

Abe: Yes, that is correct.

In other cases, responses highlight that navigating power systems often takes too long for residents and that a significant portion of the community does not bother with initiating contact with the town office if they can handle issues independently or depend on neighborhood resources.

As a result, the ability of residents to use their linking capital to mobilize the resources entrenched in these power systems and networks to access critical information is limited. Instead, groups and individuals rely heavily on their family and working relationships to meet their needs. Similarly, though Schellong (2008) states that the ability of social 
capital to penetrate resources entrenched in structures and systems is strong, the process is very complex. Especially as the ability of residents to utilize their linking capital to accomplish this goal is dependent on not just finding information but gaining knowledge of these systems. Similarly, while Aldrich and Ono (2016) and Shaw (2014) find that trustworthiness between residents and the government is essential, how reliable residents find the government is equally important. Trust does not necessarily mean given various options that one would choose to rely on the government over close friends, family, neighbors, or coworkers, even if those relationships have less capacity and resources to meet an individual's needs.

\subsection{Decision Making and Collaboration-From within Districts, Not between Districts}

Across responses, individuals explain that they often collaborate to support the needs and goals of their district rather than the overall goals of the town. As such, interest in district well-being is high, but recognition of district well-being as dependent on town wellbeing was less present. Instead, responses indicate that individuals and groups believe their district's social and economic problems require different solutions or support to remediate them compared to the town. Thus, residents conceptualize their districts as having unique relationships with problems of depopulation and industry decline. Secondly, while responses note that it is the government's responsibility to handle depopulation and industry issues, the role of district collaboration to help remediate these issues was unstated. Instead, the collective capacity of the town as a whole is questionable, as each district is operating socially and economically independent of each other. In other cases, they socially and economically compete with each other due to limited economic resources.

For example, Togura fishers' responses note their pride in their ability to work together, accomplish goals, and proactively address issues at their fishery. However, they also explain that their ability to host Togura fishermen association events is difficult due to a lack of space and parking, small accommodations, and general issues with accessibility. In addition, there are often issues with association events overlapping or even occurring on the same day between Togura, Shizugawa, and Utatsu. For example, the Awabi Matsuri (Abalone Festival) happens on the same day for Togura and Utatsu. Togura's is much smaller than Utatsu's. Similarly, Togura has fewer vendors than Utatsu and has fewer visitors per hour than Utatsu, which has wait lines starting as early as $7 \mathrm{am}$. Additionally, Togura fishers allow anyone to purchase abalone, whereas, in Utatsu, a special coupon is used to purchase abalone at a set amount and price (USD 200). Finally, Togura fishers focus on the ability of Utatsu fishers to have their events at the Hamare Market and not at the port (an inconvenient location).

Similarly, farmers express pride in their work, but that access to resources, equipment, and aid pushes them to collaborate among themselves. For example, Hatakeyama (Iriya) often shares equipment and resources with other farmers in Utatsu, such as tractors, tillers, and netting. Iriya farmers benefit from more spacious flat land to cultivate, whereas Utatsu's farmland is scattered, mountainous, and not centralized. As a result, much farming is performed entirely by hand, except for tilling. Hatakeyama expressed dissatisfaction with the amount of funding and support for farming projects, especially those unrelated to rice cultivation. However, when asked about collaborating to affect town decisions, the focus was on supporting either their district or agricultural occupations. As a result, fishers, farmers, and organizations in the community have solid collaborative ties to support their livelihoods and lifestyles, but not necessarily the power to instigate change through the local government to permanently improve their quality of life.

This distinction of solid collaboration within districts rather than across districts encapsulates feelings of the Iriya and Togura districts being less cared for. As Suzuki notes, "I understand why everything is focused on Shizugawa, but it's as if they are standing on their shoulders. We do most things on our own." Suzuki described how members of the district mostly attend events in Iriya, and that the town office promotes communal events but does not offer direct financial support. Secondly, when questioned about district 
participation, Suzuki notes, "the harvest festival is special to Iriya, so we don't have many other people come, but-no one really goes to other place's events, except for when there is an event at the fukkouichi (in Shizugawa) ... we don't go to events in other districts ... I don't mind driving but there is nothing to do in Togura, and Utatsu is far."

In this process, reconstruction has created power, social, and economic inequalities between districts. In some cases, there is a sense of superiority of the Shizugawa district, but not that the residents from Shizugawa believe themselves better than others. Instead, other districts and individuals feel less important and inferior to Shizugawa and feel they are better off handling their problems internally if possible. This insularity of districts expressed by Suzuki and others, is apparent in the lack of bridging capital between districts.

In this space, social capital has both adverse and positive effects. As individuals and groups have difficulties accessing power and information, this creates barriers to accessing government assistance and collaborating with others outside small groups or districts. However, this is not to say that social capital has not benefitted members of the community. Instead, since groups had to be self-dependent, they generated strong internal ties that act to meet their needs. As a result, there is evidence that social capital supports the collaborative capacity of groups and corroborates findings from Inaba (2011) and Shaw (2014). However, this capacity is shared between district insiders. So, unified town capacity to mitigate adverse disaster impacts is reduced due to individualized district responses to problems.

\subsection{Town Development-Responsibility, Social Infrastructure, and Economic Infrastructure}

Across all responses, there were three main areas of consensus about community needs, what the government needs to address, and the kinds of programs they would like to see in the community. First, needs and program questions initiated discussions on the differences between the kinds of social infrastructure residents want compared to economic infrastructure. Second, concerning the government, discussions centered on government responsibility and the town office doing more to address depopulation, lack of young families (and children), labor shortages, and lack of emergency funding.

For social infrastructure, this included discussions on parks, public space, nightlife, children's activities, public baths, children's and educational programs, and recreation and leisure activities. Especially for interviewees working with children or who have children, they note that there is not enough space for children to play together, such as parks, or other facilities to have fun, such as a movie theatre or gaming center. Others note that the educational development and opportunities in the town are poor, and that most high school graduates leave the community. Especially, most young adults are not interested in farming, fishing, and forestry, nor in other jobs available in the town, which mainly comprise working at a hotel, restaurant, or small store. In addition, many rate the availability of "career jobs" besides government work as poor.

Similarly, those in their 30s and 40s often remark on there not being enough activities or amenities for adults and families to enjoy, such as bars, karaoke, and restaurants, and for families, public baths, and child-friendly facilities. Elders also want greater access to public baths, and for those not close to health care facilities, greater access to those as well.

For economic infrastructure, this included discussions on transportation (e.g., buses, sidewalks, and rail), safety measures (e.g., seawall), marketplaces, shops, and industry (e.g., ports and distribution centers). Interviewees note that transportation in the town is insufficient, especially for those without a vehicle. Elderly interviewees worry about walking up and down steep hilly or mountain sidewalks to shopping centers from their neighborhoods. Others note that accessing shopping centers is difficult by bus and often necessitates multiple trips to and from home. Most interviewees without direct access to a grocery store want a store or business where they could buy necessities without having to travel to another district, town, or city.

Most fishers mentioned the seawall at least once, with their comments centering on the difficulty of operating their businesses compared to pre-seawall construction. Those 
with private ports where there is no seawall also note that the infrastructure that fishers can access is very ununiform, with some fishers processing their catches on-site and others having to use facilities father away. Especially for fishers who had the seawall constructed on their land, they feel troubled as they no longer have access to their private docks and have had to move their ships to a different location, while their processing equipment and other tools remain at their original location. As such, most fishers discuss issues with adequately being able to do their job and the added steps going from catch to distribution.

Others, such as retail and hospitality workers, government workers, and public servants, are concerned about the location, amount, and type of businesses. For those in Togura, most commute to either Shizugawa or Utatsu for work and feel that developing businesses or support for entrepreneurial activities in Togura would benefit resident wellbeing (and overall satisfaction). Utatsu and Iriya workers similarly want the construction of businesses that could support lifetime careers. In general, while not explicitly mentioned, most economic infrastructure was related to creating industry stability.

Lastly, as for the role of the town office, the top concern is depopulation, especially as to how it is contributing to school and business closures. School closures have already occurred in Iriya and Togura, but the threat to school closures in Shizugawa is deepening concerns. Among offered solutions, interviewees discuss that it is the responsibility of the town office to develop programs to encourage new young families to come to the community and to provide economic incentives to entice young entrepreneurs.

Fisher, farmer, and forester groups want the town office to exercise greater responsibility and care for their livelihoods, especially during poor harvests, heavy rains, and other natural events that affect their income and productivity. They note that the town office needs to provide an emergency fund for farmers when typhoons destroy crops that cannot be reimbursed from Japan Agriculture (JA) and for fishers when toxic algae kill off large amounts of their cultivated shellfish and other sources of their marine-based products. Individuals in these occupations feel that the risks and volatility of their jobs are not considered enough by the town office. These groups are also concerned about labor shortages and the lack of local programs to train and recruit new farmers, fishers, and foresters. In addition, they are concerned about the increasing costs, both in time and money, to find and hire outside temporary labor during peak harvest periods.

Overall, answers to community needs and programs, and what the town office needs to address, showcase that inadequate development and spending on social infrastructure has created deep inequalities. Similarly, aspects of economic development, such as the location of businesses and services, disincentives working in the community and creates difficulties for some industries to stabilize or create job security. For community needs and programs, responses highlight a lack of social infrastructure, deepening depopulation issues, as the community is unable to retain young workers and families. Similarly, the lack of infrastructure to support satisfactory and enjoyable lifestyles lowers the community's appeal to possible new migrants. As a result, underdeveloped social infrastructure is not the only issue affecting social capital utility in this study; unequal economic infrastructure also mitigates its uses. Thus, the ability for social capital to act as a recovery driver both socially and economically, as conceptualized by Aldrich (2010, 2011, 2012a); Shaw (2014); Yamamura (2010); and Shimada (2017), is low.

\section{Conclusions}

\subsection{Reconstruction Influence on the Utility of Social Capital}

The reconstruction process in Minamisanriku creates adverse situations for individuals, groups, and districts that prompt people to utilize their social capital, but also restricts their utility of it. Especially for this case, social capital provides residents the ability to meet their immediate needs and support their livelihoods. However, as other capitals are scarce in the community, over-reliance on social capital creates social and political dynamics that fortify strong in group-out group behaviors. As such, the ability of residents to utilize their social capital to address social and economic problems is limited to the scope of their 
district. Overall, the importance of social capital in this community is its ability to fill in gaps, structural holes, and bridge the needs of residents left behind by the reconstruction process. However, the use of social capital in this way is not sustainable, since larger problems of depopulation and industrial decline are only stemmed temporarily, instead of resolved permanently through development projects centered on social and economic infrastructure.

Similarly, the top-down nature of the reconstruction process and the extreme disenfranchisement of some districts, such as Togura, create a sentiment that the survival of other districts, such as Shizugawa, is more important. Thus, other district members recognize this lack of care, especially through the inequitable distribution of funding and investment and a lack of projects. As a result, these members turn away from engaging with the reconstruction process as it is seen as an unfair system. In this case, social capital is insufficient to bridge these political conflicts, but does provide districts some internal capacity to handle concerns they deem important more quickly by having to not rely upon other agencies or bureaucratic systems.

\subsection{Social Capital as an Asset to Driving Economic Growth, Recovery, Collaboration, and Decision Making}

Social capital as an asset for residents appears in their work collaborations, especially for fishers and farmers. In this case, social capital is used by these groups to coordinate the sharing of resources and equipment, meet group interests, and manage problems. Similarly, as seen in Togura, social capital drives the collaboration of the 96 cooperative fishers and 36 oyster union members. However, these collaborations do not necessarily enable these groups to address larger power structures. As such, social capital's ability to galvanize larger collective action that encourages residents to engage governance structures is limited. Thus, social capital alone does not have the power to drive recovery in this community, and the scope of its influence to improve the economic and social well-being of residents is highly sensitive to other disparities and inequalities.

Moreover, issues with community unity due to both a history of mergers and reconstruction planning mean that residents are working in smaller independent groups to address issues that may be best treated through broader unified and collaborative efforts to more efficiently handle both district and town problems. As a result, residents do not get the full potential use value out of the social capital they do possess. Similarly, the town office's lack of recognition of troubles with unity and lack of supporting resident participation may further prolong the recovery process and continue to leave critical social and economic problems untreated.

\subsection{The Role of Linking Capital}

Decision making as represented by linking capital reveals that residents are disenfranchised, have difficulties navigating power structures, and have difficulties utilizing the embedded resources in their social networks to engage these systems effectively. Additionally, the ability of linking capital to drive inclusive decision making is affected by who comprises these linking relationships, and how these individuals interact with others. If linked members engage the public frequently and other individuals outside their in group, it is easier for residents to access power and information. However, as evidenced in this study, linked individuals are also just as likely to only engage with other linked individuals, keeping power insulated from others. This is because linking capital is highly sensitive to the bureaucratic and social culture it is a part of. As such, the utility of linking capital is predicated upon norms and values that found social and power hierarchies. Lastly, despite the high amount of linking capital in the community, most of this is retained by men and women's connection to linking individuals is much smaller. As such, there are also gender inequities in accessing or creating linking capital. These gender inequities span across districts rather than being isolated to a single district. As a result, women across the town may be experiencing inequality in a higher proportion to men, as they have less 
access to formal institutions of power, and especially because this access is more likely to be brokered by men.

\subsection{Future Social Capital Disaster Studies and Reconstruction Planning in Japan}

Social capital disaster studies in Japan have come far in measuring and explaining certain positive and negative recovery outcomes (Yamamura 2010; Inaba 2011; Aldrich 2012a; Shaw 2014; Shimada 2017; Ye and Aldrich 2019; Sasaki et al. 2020). However, social capital disaster studies may be generally missing critical contextual information that explains the influence of social capital versus the utility of social capital as an asset. Additionally, the kind of proxies these projects utilize should be critically evaluated based on their scope and the extent to which they can explain community contexts. Similarly, this study is also limited in scope, due to primarily relying on social networks as a proxy for social capital and on interviews to capture and explain social, political, and economic contexts in this community. Additionally, as the project was completed during the COVID19 pandemic, some additional components were not possible to complete, such as hosting additional town forums, and other participatory components that may have provided additional insight to collaboration in the community.

Future social capital disaster studies, if possible, should also use a variety of qualitative and quantitative methods to collect data from their case sites to ensure they accurately capture how social capital functions for individuals in day-to-day use, such that broad influences of social capital can be differentiated from intermediating forces. Additionally, the creation of such studies would help to pinpoint which qualitative measures of social capital best explain recovery outcomes. Similarly, social capital disaster studies should take care in documenting the effects of social norms and culture influencing the creation and use of bonding, bridging, and linking capitals, especially when considering issues of gendered access to power.

In terms of redevelopment, while it may be bureaucratically efficient to focus development in a centralized location, such as Shizugawa, this process directly disenfranchises other districts and makes it more difficult to access resources. This in turn reduces the well-being, happiness, and satisfaction for a majority of residents. As a result, while this is not a new insight, this study reinforces calls by other scholars that redevelopment and reconstruction planning should use a holistic approach to developing communities in order to properly address inequities. Similarly, over-investing in one district makes other districts needlessly more vulnerable to future disasters and greatly threatens the future existence of those districts. Thus, redevelopment and reconstruction planning projects in Japan should look to serve the interests of the entire community rather than a select few to avoid creating or to avoid worsening social, political, and economic problems.

While this study provides nuance to the utility of social capital in this particular community, there is still much to do about ways to improve disaster recovery outcomes. Additionally, more work needs to be performed to study vulnerable groups to understand their use of social capital, such as the elderly, underemployed, mothers, and other groups who tend to be removed from critical recovery resources. Especially in this case, future work has already begun on interviewing young leaders and other highly collaborative organizations to investigate other possible explanations to the phenomenon uncovered in this study and to create new community programs to meet resident needs.

Funding: This research was funded by the Japan-US Educational Commission (JUSEC) under Fulbright Japan. The APC was funded by the author.

Institutional Review Board Statement: This study was given exempt status by the Institutional Review Board and Human Research Protection Program at the author's institution.

Informed Consent Statement: Informed consent was always obtained orally before interviews and survey distribution meetings and reaffirmed during interviews and survey distribution. All participants were provided a copy of the consent form in Japanese. Once the research became socially distanced due to COVID-19, all mailed surveys had a consent form sent first, followed by contact 
from the author to confirm participation and answer questions. Upon receiving confirmation, the survey was mailed to the participant with return postage.

Data Availability Statement: The data presented in this study are available on request from the corresponding author as long as this does not infringe with the privacy of interviewees participating in this study. The data are not publicly available due to potential infringements of confidentiality, terms of the consent form, and language in which the data were recorded.

Acknowledgments: I would like to thank my community partners for their time, knowledge, perseverance, and commitment to the success of this project, and for their friendship. I would like to give special thanks to the professors at Kyoto University and Tohoku University who also provided invaluable input.

Conflicts of Interest: The author declares no conflict of interest.

\section{Appendix A}

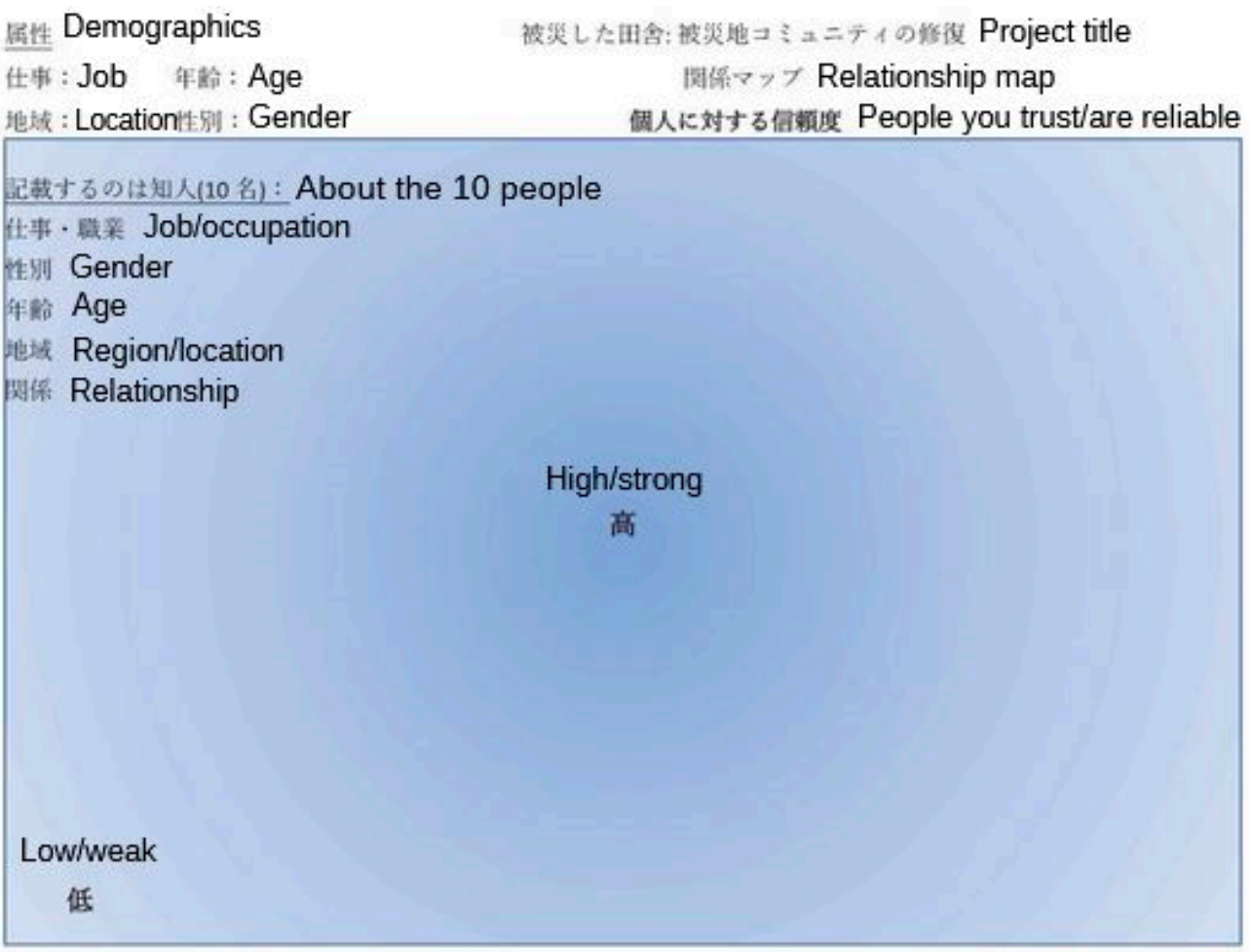

Figure A1. Mapping exercise instrument.

\section{Appendix B}

Interview Questions and Protocol

Thank you for meeting with me today. I wanted to ask for your voluntary input on some questions I have about your life and your participation in the community. This is related to the mapping exercise we completed earlier about your relationships in Minamisanriku. These questions focus on community change and how much power you think you have in the community. It is our goal to talk with people like you to understand their role in the community and how they would like to see the community change. Please feel free to stop me to ask questions or if you would like to end the interview at any time. This interview should take approximately an hour. Is it okay to record this interview? Would you like a copy of the recording? How would you like to receive updates on this project? (email, mail, community partner newsletter).

For each of the following questions please tell me how you would respond. Please also think about reasons why you may agree or disagree with these questions. If you are 
uncomfortable with any question please circle it, and I will not ask you it. Before we begin do you have any questions?

1. Can you influence decisions that affect your life?

2. Are you satisfied with the amount of influence you have over decisions that affect your life?

3. Can you influence decisions that affect your neighborhood?

4. Are you satisfied with the amount of influence you have over decisions that affect your neighborhood?

5. By working together with others, can you influence decisions that affect your neighborhood?

6. Does your neighborhood have influence over things that affects your life?

7. Can you influence decisions that affect your area (Shizugawa, Togura, Utatsu, Iriya)?

8. Are you satisfied with the amount of influence you have over decisions that affect your area (Shizugawa, Togura, Utatsu, Iriya)?

9. Can you influence decisions that affect Minamisanriku?

10. Are you satisfied with the amount of influence you have over decisions that affect Minamisanriku?

11. By working together, can people in your neighborhood influence decisions that affect Minamisanriku?

12. Do people in your neighborhood have connections to people who can influence what happens within Minamisanriku?

13. What sort of new programs do you want in Minamisanriku? Why?

14. What do you think the current needs of Minamisanriku are? Are these different from what your neighborhood/district needs or are they the same?

15. What needs would you like the local government to address? Have they addressed these in the past?

(Above Interview Questions and Protocol are Adapted from Israel et al. 2012).

\section{References}

Aldrich, Daniel P. 2010. Fixing recovery, social capital in post-crisis resilience. Journal of Homeland Security 6: 1-10.

Aldrich, Daniel P. 2011. The Power of People: Social capital's Role in Recovery from the 1995 Kobe Earthquake. Natural Hazards 56: 595-611. [CrossRef]

Aldrich, Daniel P. 2012a. Building Resilience: Social Capital in Post-Disaster Recovery. Chicago: The University of Chicago Press.

Aldrich, Daniel P. 2012b. Social, Not Physical, Infrastructure: The Critical Role of Civil Society after the 1923 Tokyo Earthquake. Disasters 36: 398-419. [CrossRef] [PubMed]

Aldrich, Daniel P., and Michelle A. Meyer. 2015. Social Capital and Community Resilience. The American Behavioral Scientist 59: 254-69. [CrossRef]

Aldrich, Daniel P., and Yoshikuni Ono. 2016. Local politicians as linking social capital: An empirical test of political behavior after Japan's 3/11 disasters. Natural Hazards 84: 1637-59. [CrossRef]

Arias, Valera. 2015. Community knowledge sharing and co-production of water services: Two cases of community aqueduct associations in Colombia. Water Alternatives 8: 77-98.

Blackwell, Angela, and Raymond Colmenar. 2000. Community building: From local wisdom to Public Policy. Public Health Reports 115: 161-66. [CrossRef]

Bourdieu, Pierre. 1986. Forms of capital. In Handbook of Theory and Research for the Sociology of Education. Edited by John Richardson. Westport: Greenwood Press, pp. 241-60.

Briggs, Xavier. 2003. Social capital, types of. In The Encyclopedia of Community: From the Village to the Virtual World. Edited by Levinson David and Karen Christensen. Thousand Oaks: Sage, pp. 1277-83.

Campbell, Christopher. 2000. Social structure, space and sentiment: Searching for common ground in sociological conceptions of community. In Research in Community Sociology. Edited by Chekki Dan. London: JAI Press, pp. 21-57.

Cheek, Wesley. 2020. The Paradox of Community Involvement: Rebuilding Minamisanriku. Disaster Prevention and Management Ahead-of-print. , 893-907. [CrossRef]

DiIulio, John J. 1996. Help Wanted: Economists, Crime and Public Policy. The Journal of Economic Perspectives 10: 3-24. [CrossRef]

Esri. 2020. "Cho Cho Moku Boundaries" (Basemap). Scale not Given. "Map of Minamisanriku by District." Available online: https:/ / services.arcgis.com/P3ePLMYs2RVChkJx/arcgis/rest/services/JPN_Boundaries_2020/FeatureServer (accessed on 20 June 2021).

Flora, Cornelia B., Jan L. Flora, and Stephen P. Gasteyer. 2016. Rural Communities: Legacy and Change. Boulder: Westview Press. 
Fraser, Timothy, Daniel Aldrich, Andrew Small, and Andrew Littlejohn. 2021. In the Hands of a Few: Disaster Recovery Committee Networks. Journal of Environmental Management 280: 111643. [CrossRef]

Fukao, Masataka. 2019. Community Foundations and Social Investments in Japan. In Depopulation, Deindustrialisation and Disasters: Building Sustainable Communities in Japan. Edited by Shiraishi Katsutaka and Nobutaka Matoba. Cham: Palgrave Macmillan, pp. 335-51. [CrossRef]

Fukuyama, Francis. 2001. Social Capital, Civil Society and Development. Third World Quarterly 22: 7-20. [CrossRef]

Gill, Tom. 2014. Review of the book Building resilience: Social capital in post-disaster recovery by Aldrich, Daniel. Social Science Japan Journal 17: 118-22. [CrossRef]

Gold, Steven J., and Ivan Light. 2000. Ethnic Economies and Social Policy. In Research in Social Movements, Conflicts and Change. Edited by Patrick G. Coy. Ohio: Emerald Group Publishing Limited, vol. 22, pp. 165-91. [CrossRef]

Goulding, Christina, Mihaela Kelemen, and Toru Kiyomiya. 2018. Community based response to the Japanese tsunami: A bottom-up approach. European Journal of Operational Research 268: 887-903. [CrossRef]

Hawkins, Robert L., and Katherine Maurer. 2010. Bonding, Bridging, and Linking: How Social Capital Operated in New Orleans Following Hurricane Katrina. British Journal of Social Work 40: 1777-93. [CrossRef]

Hurlbert, Jeanne S., John J. Beggs, and Valerie A. Haines. 2001. Social Networks and Social Capital in Extreme Environments. In Social Capital: Theory and Research. Edited by Lin Nan, Karen S. Cook and Ronald S. Burt. New York: Aldine de Gruyter, pp. $209-31$.

Inaba, Youji. 2011. How to Develop Social Capital—A Perspective from Policy Making (Shakai Kankei Shihon wo Dou Jousei Surunoka-Seusaku Taisyo to Shiteno Shiten). Tokyo: DIO Research Institute for Advancement of Living Standards.

Israel, Barbara A., Eugenia Eng, Edith A. Parker, and Amy J. Schulz. 2012. Methods for Community-Based Participatory Research for Health, 2nd ed. Somerset: Jossey-Bass.

Ivankova, Nataliya V. 2015. Mixed Methods Applications in Action Research: From Methods to Community Action. Thousand Oaks: SAGE Publications.

James, Helen, and Douglas Paton. 2016. The Consequences of Disasters: Demographic, Planning, and Policy Implications. Springfield: Charles C. Thomas, Publisher, Ltd.

Kaneko, Yuka. 2017. Reconstruction of communities: Lessons from Hanshin-Awaji Earthquake and East Japan Earthquake. In Community-Based Reconstruction of Society. Edited by Hokugo Akihiko and Yuka Kaneko. Kobe University Social Science Research Series; Singapore: Springer Nature, pp. 13-17. [CrossRef]

Knack, Stephen, and Philip Keefer. 1997. Does social capital have an economic payoff? A cross country investigation. The Quarterly Journal of Economics 112: 1251-88. [CrossRef]

Levine, Sheen S., Evan P. Apfelbaum, Mark Bernard, Valerie L. Bartelt, Edward J. Zajac, and David Stark. 2014. Ethnic diversity deflates price bubbles. Proceedings of the National Academy of Sciences of the United States of America 111: 18524-29. [CrossRef]

Littlejohn, Andrew. 2017. After the Flood: The Politics of Reconstruction in Post-3.11 Tohoku. Ph.D. thesis, Harvard University, Cambridge, MA, USA.

Marín, Andrés, Örjan Bodin, Stefan Gelcich, and Beatrice Crona. 2015. Social capital in post-disaster recovery trajectories: Insights from a longitudinal study of tsunami-impacted small-scale fisher organizations in Chile. Global Environmental Change 35: 450-62. [CrossRef]

Mathbor, Golam M. 2007. Enhancement of community preparedness for natural disasters the role of social work in building social capital for sustainable disaster relief and management. International Social Work 50: 357-69. [CrossRef]

Mertens, Donna M. 2013. Emerging advances in mixed methods: Addressing social justice. Journal of Mixed Methods Research 7: 215-18. [CrossRef]

Minamisanriku Town Office. 2010. Town Statistics. Available online: https://www.town.minamisanriku.miyagi.jp/index.cfm/10,793 ,c,html/793/2098.pdf (accessed on 14 March 2021).

Minamisanriku Town Office. 2011. Intention Survey. (Results of Intention Survey on "Reconstruction Town Development in Minamisanriku Town"). Available online: https://www.town.minamisanriku.miyagi.jp/index.cfm/6,301,c,html/301/2218.pdf (accessed on 14 March 2021).

Minamisanriku Town Office. 2012. Minamisanriku Town Earthquake Reconstruction Plan. Available online: https://www.town. minamisanriku.miyagi.jp/index.cfm/6,303,c,html/303/m-f-gaiyo.pdf (accessed on 14 March 2021).

Minamisanriku Town Office. 2015. Town Statistics. Available online: https:/ /www.town.minamisanriku.miyagi.jp/index.cfm/10,793 ,c,html/793/20160323-161759.pdf (accessed on 14 March 2021).

Minamisanriku Town Office. 2017. Minamisanriku Reconstruction Status. (Reconstruction Status after the Great East Japan Eathquake, Minamisaniku Town Conditions). Available online: https://www.town.minamisanriku.miyagi.jp/index.cfm/6,7752,c,html/77 52/20150527-191250.pdf (accessed on 14 March 2021).

Minamisanriku Town Office. 2020. Town Statistics. Available online: https://www.town.minamisanriku.miyagi.jp/index.cfm/10,793 ,c,html/793/20210414-150022.pdf (accessed on 14 March 2021).

Ministry of Agriculture, Forestry and Fisheries. 2005. Agriculture and Forestry Census Report. Available online: https://www.maff.go. jp/j/tokei/census/afc/2010/05kekka.html (accessed on 14 March 2021).

Ministry of Agriculture, Forestry and Fisheries. 2008. Fishery Census. Available online: https://www.maff.go.jp/j/tokei/census/fc/ 2008/report/index.html (accessed on 14 March 2021). 
Ministry of Agriculture, Forestry and Fisheries. 2010. Agriculture and Forestry Census Report. Available online: https://www.maff.go. jp/j/tokei/census/afc/about/2010.html (accessed on 14 March 2021).

Ministry of Agriculture, Forestry and Fisheries. 2013. Fishery Census. Available online: https://www.maff.go.jp/j/tokei/census/fc/ 2013/report/index.html (accessed on 14 March 2021).

Ministry of Agriculture, Forestry and Fisheries. 2015. Agriculture and Forestry Census Report. Available online: https://www.maff.go. jp/j/tokei/census/afc2015/280624.html (accessed on 14 March 2021).

Ministry of Agriculture, Forestry and Fisheries. 2018. Fishery Census. Available online: https://www.maff.go.jp/j/tokei/census/fc/ 2018/200313.html (accessed on 14 March 2021).

Ministry of Agriculture, Forestry and Fisheries. 2020. Agriculture and Forestry Census Report. Available online: https://www.maff.go. $\mathrm{jp} / \mathrm{j} /$ tokei/census/afc/2020/index.html (accessed on 14 March 2021).

Minkler, Meredith, and Nina Wallerstein. 2005. Improving health through community organization and community building: A health education perspective. In Community Organizing and Community Building for Health, 2nd ed. Edited by Minkler Meredith. New Brunswick: Rutgers University Press, pp. 26-50.

Norris, Fran H., Susan P. Stevens, Betty Pfefferbaum, Karen F. Wyche, and Rose L. Pfefferbaum. 2008. Community resilience as a metaphor, theory, set of capacities, and strategy for disaster readiness. American Journal of Community Psychology 41: 127-50. [CrossRef]

Ota, Naofumi. 2019. The Development of Disaster Management Laws and Systems after the Great East Japan Earthquake, and Local Resilience. In Depopulation, Deindustrialisation and Disasters: Building Sustainable Communities in Japan. Edited by Shiraishi Katsutaka and Nobutaka Matoba. Cham: Palgrave Macmillan, pp. 293-313. [CrossRef]

Pham, Theresa Thao. 2016. Engagement in knowledge production, authentication, and empowerment: A community-based participatory research project with Moroccan immigrants in Spain. International Social Work 59: 368-80. [CrossRef]

Pigg, Kenneth, Stephen Gasteyer, Kenneth Martin, Godwin Apaliyah, and Kari Keating. 2015. Community Effects of Leadership Development Education: Citizen Empowerment for Civic Engagement. Morgantown: West Virginia University Press.

Portes, Alejandro, and Patricia Landolt. 2000. Social Capital: Promise and Pitfalls of Its Role in Development. Social Capital: Promise and Pitfalls of Its Role in Development. Journal of Latin American Studies 32: 529-47. Available online: http://www.jstor.org/ stable/158574 (accessed on 20 June 2021). [CrossRef]

Portes, Alejandro. 2014. Downsides of social capital. Proceedings of the National Academy of Sciences of the United States of America 111: 18407-8. [CrossRef]

Putnam, Robert, Ivan Light, Xavier de Souza Briggs, William M. Rohe, Avis C. Vidal, Judy Hutchinson, Jennifer Gress, and Michael Woolcock. 2004. Using Social Capital to Help Integrate Planning Theory, Research, and Practice: Preface. Journal of the American Planning Association 70: 142-92. [CrossRef]

Putnam, Robert. 2000. Bowling Alone: The Collapse and Revival of American Community. New York: Simon \& Schuster.

Rosengren, Åsa, Ann-Marie Lindqvist, and Ilse Julkunen. 2014. Towards an inclusive knowledge base for community-based research and sustainable knowledge production. Nordic Social Work Research 4: 86-101. [CrossRef]

Sadri, Arif Mohaimin, Satish V. Ukkusuri, Seungyoon Lee, Rosalee Clawson, Daniel Aldrich, Megan Sapp Nelson, Justin Seipel, and Daniel Kelly. 2018. The role of social capital, personal networks, and emergency responders in post-disaster recovery and resilience: A study of rural communities in Indiana. Natural Hazards 90: 1377-406. [CrossRef]

Sasaki, Yuri, Jun Aida, and Hiroko Miura. 2020. Social capital in disaster-affected areas. Journal of the National Institute of Public Health 69: 25-32. [CrossRef]

Schellong, Alexander R. M. 2008. Government 2.0: An Exploratory Study of Social Networking Services in Japanese Local Government. Transforming Government 2: 225-42. [CrossRef]

Sekine, Kae, and Alessandro Bonanno. 2016. The Contradictions of Neoliberal Agri-Food, Corporations, Resistance, and Disasters in Japan. Morgantown: West Virginia University Press.

Shaw, Rajib. 2014. Community Practices for Disaster Risk Reduction in Japan. Tokyo: Springer Japan.

Shimada, Go. 2015. The role of social capital after disasters: An empirical study of Japan based on Time-Series-Cross-Section (TSCS) data from 1981 to 2012. International Journal of Disaster Risk Reduction 14: 388-94. [CrossRef]

Shimada, Go. 2017. A quantitative study of social capital in the tertiary sector of Kobe-Has social capital promoted economic reconstruction since the great hanshin awaji earthquake? International Journal of Disaster Risk Reduction 22: 494-502. [CrossRef]

Shinoyama, Kenji. 2013. Disaster management and risk management, and administrative law. (Bousai Saigai Risk Kanri to Gyoseihougaku. Ho no Kagaku 44: 29-38. (In Japanese)

Shiraishi, Katsutaka, and Nobutaka Matoba. 2019. Depopulation, Deindustrialisation and Disasters: Building Sustainable Communities in Japan. Cham: Palgrave Macmillan. [CrossRef]

Szreter, Simon, and Michael Woolcock. 2004. Health by Association? Social Capital, Social Theory and the Political Economy of Public Health. International Journal of Epidemiology 33: 650-67. [CrossRef]

Tierney, Kathleen. 2019. Disasters a Sociological Approach. Cambridge and Medford: Polity Press.

Todo, Yasuyuki, Kentaro Nakajima, and Petr Matous. 2013. How do Supply Chain Networks Affect the Resilience of Firms to Natural Disasters? Evidence from the Great East Japan Earthquake, RIETI Policy Discussion Paper Series. Journal of Regional Science 55: 209-29. [CrossRef] 
Torsvik, Gaute. 2000. Social Capital and Economic Development: A Plea for the Mechanisms. Rationality and Society 12: 451-76. [CrossRef]

Waldinger, Rodger. 1995. The 'other side' of embeddedness: A case study of the interplay between economy and ethnicity. Ethnicity and Racial Studies 18: 555-80. [CrossRef]

Ward, Kayleigh. 2018. Beyond Recovery: Rural Tohoku Local Politics, Governance, and the Erosion of Social Capital during Reconstruction. Master's thesis, Michigan State University, Ann Arbor, MI, USA.

Woolcock, Michael. 2001. The place of social capital in understanding social and economic outcomes. Canadian Journal of Policy Research 2: $11-17$.

Yamamura, Eiji. 2010. Effects of interactions among social capital, income and learning from experiences of natural disasters: A case study from Japan. Regional Studies 44: 1019-32. [CrossRef]

Ye, Maoxin, and Daniel P. Aldrich. 2019. Substitute or complement? How social capital, age and socioeconomic status interacted to impact mortality in Japan's 3/11 tsunami. SSM-Population Health 7: 100403. [CrossRef]

Yen-Kohl, Ellen, and The Newtown Florist Club Writing Collective. 2016. "We've been studied to death, we ain't gotten anything": (re)claiming environmental knowledge production through the praxis of writing collectives. Capitalism, Nature, Socialism 27: 52-67. [CrossRef]

Yotsui, Mihoku, Catherine Campbell, and Teruo Honma. 2016. Collective Action by Older People in Natural Disasters: The Great East Japan Earthquake. Ageing and Society 36: 1052-82. [CrossRef] 